\title{
The Value of Improved Wind Power Forecasting: Grid Flexibility Quantification, Ramp Capability Analysis, and Impacts of Electricity Market Operation Timescales
}

\author{
Qin Wang, Hongyu Wu, Anthony R. Florita, \\ Carlo Brancucci Martinez-Anido, Bri-Mathias Hodge ${ }^{1}$ \\ National Renewable Energy Laboratory, Golden, CO 80401, USA
}

\begin{abstract}
The value of improving wind power forecasting accuracy at different electricity market operation timescales was analyzed by simulating the IEEE 118-bus test system as modified to emulate the generation mixes of the Midcontinent, California, and New England independent system operator balancing authority areas. The wind power forecasting improvement methodology and error analysis for the data set were elaborated. Production cost simulation was conducted on the three emulated systems with a total of 480 scenarios considering the impacts of different generation technologies, wind penetration levels, and wind power forecasting improvement timescales. The static operational flexibility of the three systems was compared through the diversity of generation mix, the percentage of must-run base-load generators, as well as the available ramp rate and the minimum generation levels. The dynamic operational flexibility was evaluated by the real-time upward and downward ramp capacity. Simulation results show that the generation resource mix plays a crucial role in evaluating the value of improved wind power forecasting at different timescales. In addition, the changes in annual operational electricity generation costs were mostly influenced by the dominant resource in the system. Finally, the impacts of pumped-storage resources, generation ramp rates, and system minimum generation level requirements on the value of improved wind power forecasting were also analyzed.
\end{abstract}

Keywords: Wind power integration; wind power forecasting; grid flexibility; ramp capability; operation timescales; storage

\section{Introduction}

The variability and uncertainty of wind power can require changes to power system operating procedures as increasing amounts of wind generation are incorporated into the generation mix [1]. With increased investments in wind power fueled by state renewable portfolio standards [2] and declining wind power costs [3,4], the electric grids in the United States are starting to face operational challenges. One of the most efficient approaches to mitigating the negative impacts of wind power on system operations is to incorporate short-term wind power forecasting. With the application of new statistical and machine learning methodologies, as well as advancements in numerical weather prediction (NWP) models, the accuracy of wind power forecasting has been improved significantly in recent years. For example, the day-ahead (DA in tables) wind

\footnotetext{
${ }^{1}$ Corresponding author. Tel: +1-303-384-6981

E-mail address: bri.mathias.hodge@nrel.gov (Bri-Mathias Hodge)

Page | 1
} 
power forecasting mean absolute error (MAE) for a 100-MW nameplate capacity wind power plant has been reduced from $12 \%$ in 2006 to $10 \%$ in 2015, and the hour-ahead wind power forecasting MAE of the same site has been reduced from 12\% in 2006 to $7 \%$ in 2015 [5]. A general review of the state of the art in the short-term prediction of wind power is shown in [6].

A plethora of wind power forecasting techniques currently exist, including NWP models, statistical models, machine learning methods, and space-time trajectories [7-10]. The NWP approach is primarily used to forecast wind speeds multiple hours to days ahead for given sites, and the wind speed is converted to wind power based on the wind turbine's power output curve [11-14]. The statistical models and machine learning methods attempt to adjust the relationships among a set of inputs, including the NWP model output and other meteorological data, and past measurements of the wind power output at a given location [15-17]. A recent trend in wind power forecasting is the emergence of probabilistic forecasting approaches, which are distinct from the traditional point forecasting approach in that the latter provides only a single estimated value (which is often the most likely outcome) for a given look-ahead horizon, whereas the former can provide probabilistic information about future events [18-20]. The trajectory method generalizes probabilistic forecasting by accounting for spatiotemporal dependencies [10]. In recent years, wind power ramp forecasting, which focuses on improving forecasts related to extreme events in the form of large power output variations, has attracted growing interest in the wind power forecasting community [21].

Recent research shows that standard wind power forecasts can be improved by $30 \%$ with advanced machine learning techniques [22], and the trend of expecting more accurate forecasts is expected to continue as wind power penetration rates increase; however, it is not clear how the improved accuracy will impact the operation of electric grids. It is difficult to precisely gauge the value attributed to a certain extent of wind forecast improvements because the relationship depends on multiple factors, such as market structure and size, wind penetration level, and forecasting timescales. Botterud et al. [23] reviewed the application of wind power forecasting in major U.S. electricity markets. Wang et al. [24] investigated the impacts of wind power forecasting uncertainty on the unit commitment process, but they did not measure the benefits from improved power forecasting. Hodge et al. [25] attempted to quantify the value of improved ultra-short-term wind power forecasting. A similar study also examined the value of day-ahead solar power forecasting improvements in the Independent System Operator New England (ISONE) power system [26]. McGarrigle et al. [27] studied the value of improved wind energy forecasts in the 2020 Irish electricity system with a $33 \%$ wind penetration level. Nevertheless, the majority of these studies have attempted to quantify the value of wind power forecasting only at a single time horizon, and they did not consider the impacts of grid flexibility and the system's ramp capability. The authors' previous study [28] quantified the benefits of wind power forecasting improvement in terms of production costs as well as grid reliability. The major difference between this article and reference [28] is that this article extends the scope in [28] by considering the impacts of grid flexibility, ramp capability, and electricity market operation timescales.

The techniques in this paper utilized the accuracy of wind power forecasts varied at different time horizons. For example, the MAE for 4-hour-ahead (4HA) forecasts is typically smaller than that for day-ahead forecasts because the 4HA forecast horizon is closer to real time, and thus 
more recent information is available. Improving the wind power forecasting accuracy at different time horizons can bring different benefits to the electric grid. From a utility's perspective, because the forecast accuracy and the resources required for the forecast vary at different timescales, there is a need to understand which timescale can bring the maximum benefits. This would guide investments in improving the forecast accuracy in day-ahead only, in intraday only, or in both day-ahead and intraday. In addition, the value of wind power forecasting improvement varies in systems with different flexibility levels and ramp capabilities. For instance, to date the California Independent System Operator (CAISO) power system has almost 20\% renewable energy sources, and large ramp-up (and ramp-down) capability from the conventional generation fleet is required during the sunset (sunrise) period. This is illustrated by the "duck curve" [29], wherein the presence of solar energy makes the previous load shape (known as an "elephant curve") change to show the net load (i.e., load minus variable renewables) in the shape of a duck. However, the Midcontinent Independent System Operator (MISO) power system has approximately only $10 \%$ renewable energy sources (mostly from wind power) and has more than $60 \%$ coal [30]. Increasing the accuracy of wind power forecasting by the same amount in the two systems will incur different values. How to quantify the value of wind power forecasting improvements under different grid flexibility levels and ramp capabilities is a significant yet unresolved issue. To address these challenges, this article investigates the value of wind power forecasting improvements at different operation horizons as well as analyzes the impacts of grid flexibility and ramp capability. The study was performed by simulating the operation of an IEEE 118-bus test system ${ }^{2}$ [31] as modified to emulate the generation mixes of the CAISO, ISO-NE, and MISO balancing authority areas (BAA). For each BAA, 10 wind power penetration levels and six wind power forecasting improvement scenarios are simulated. These scenarios are compared on an operational cost basis (called generation production costs) for all generators, including 1) start-up and showdown costs, 2) variable operation and maintenance (O\&M) costs, and 3) fuel costs. The fixed O\&M costs are not considered because they are generally used only for long-term generation capacity planning in PLEXOS. For the same reason, the levelized cost of electricity and the capital costs of generators are excluded when calculating the generation production costs. The impacts on wind power curtailment at different operation horizons are also compared. Moreover, operational impacts on conventional generators are analyzed.

The rest of the paper is organized as follows. Section 2 describes the process of generating the wind power forecasting improvement data in the different scenarios. Section 3 presents the production cost simulation model and the input data sources for the model. Section 4 demonstrates the study results. Finally, Section 5 concludes.

\section{Wind Power Forecasting Improvement Methodology and Error Analysis}

The National Renewable Energy Laboratory (NREL)'s Wind Integration National Dataset (WIND) Toolkit was the source of the wind power data used for different wind penetration scenarios. In the development of the tool kit, measured wind data sets served as reanalysis inputs to ensure realistic spatiotemporal correlations, ramping characteristics, and capacity factors of the simulated wind power plants. Further, these data are time synchronized with available load

\footnotetext{
${ }^{2}$ The IEEE 118-bus test case represents a simple approximation of the American Electric Power system (in the U.S. Midwest) as of December 1962. The IEEE 118-bus system contains 54 generators, 186 transmission lines, and 91 loads [31].

Page | 3
} 
profiles. The WIND Toolkit is the most comprehensive publicly available data set that includes meteorological data, time series data of wind power production, and simulated forecasts. The data set was created using the Weather Research and Forecasting model run on an approximately 2-km by 2-km grid at 5-minute resolution for the entire continental United States, with millions of meteorological data points narrowed down to 126,000 feasible land-based and offshore wind power production sites according to capacity factors and geographic information system exclusions [32].

The site selection process was a major component of the wind power and forecast data generation process. Wind power data from the California BAA was used for all the simulations, as shown in the appendix, Figure A.1, including the identification of sites, Table A.1, and details on levels of aggregation for each scenario, Table A.2. The candidate wind sites were selected from within the available WIND Toolkit sites using a greedy algorithm that prioritized locations geographically near load centers. That is, it was necessary to establish the number of turbines, $n$ (which refers to the number of wind turbines that constitute a "wind power plant"), composing each of the 10 "wind power plants" shown in the appendix. First, the top 10 load centers were identified within the 118-bus model. The algorithm then searched the WIND Toolkit for the wind power plants nearest the load center, with the highest capacity factor, until the desired capacity was reached. The plants were scaled slightly down to exactly match the desired wind capacity (equally distributed at each of the 10 locations) in the development of a given scenario; Appendix A details how individual wind turbines were successively aggregated.

Once the set of wind power plants for a given scenario was identified, it was possible to simply query the database to obtain the day-ahead and 4HA forecast time series associated with each plant. These, too, were aggregated to create a balancing area level forecast time series, which could then be utilized in the power system models described below. For the concerns of this study, and because of the computational complexity of the power system models, it was decided that forecast improvements would be technology agnostic and in the fashion of uniform improvements. That is, irrespective of technologies currently available, it was assumed that wind power improvements of $20 \%, 40 \%, 60 \%, 80 \%$, and $100 \%$ (perfect forecasts) at all points in the time series were possible, to assess the value of wind power forecasting improvements. Uniform improvements were chosen because how the timing of forecast improvements aligns with certain power system operational conditions can greatly impact their value. Obviously, improvements in forecasting methods will be greater during certain times or meteorological conditions than others. Although the timing of these improvements will have significance for the economics of the power system, the uniform improvement approach was adopted in this study because of the computational complexity of modeling the exact timing of the improvements. The uniform improvements provide a good indication of the economic improvements that could be expected from general forecasting improvements, without adding the computational complexity of specifying the times most likely to have forecast improvements. The benchmark case, $0 \%$ improvement (state-of-the-art forecasting), provides the reference for examining the possible improvements in production costs and reliability. As shown in Section 3.1, 10 wind penetration levels are simulated for each BAA, ranging from $5.87 \%$ to $51.64 \%$. In the rest of this section, we select data from the 10 scenarios for demonstration. 
Figure 1 provides an example of the both day-ahead and 4HA forecast error distributions, with the illustration juxtaposing the extrema of both expected forecast errors and scenarios. That is, without regard to perfect forecasts, state-of-the-art day-ahead and 4HA forecasts with $80 \%$ improvement are most and least erroneous, respectively, and Scenario \#1 and Scenario \#10 have the least and most levels of wind penetration, respectively.
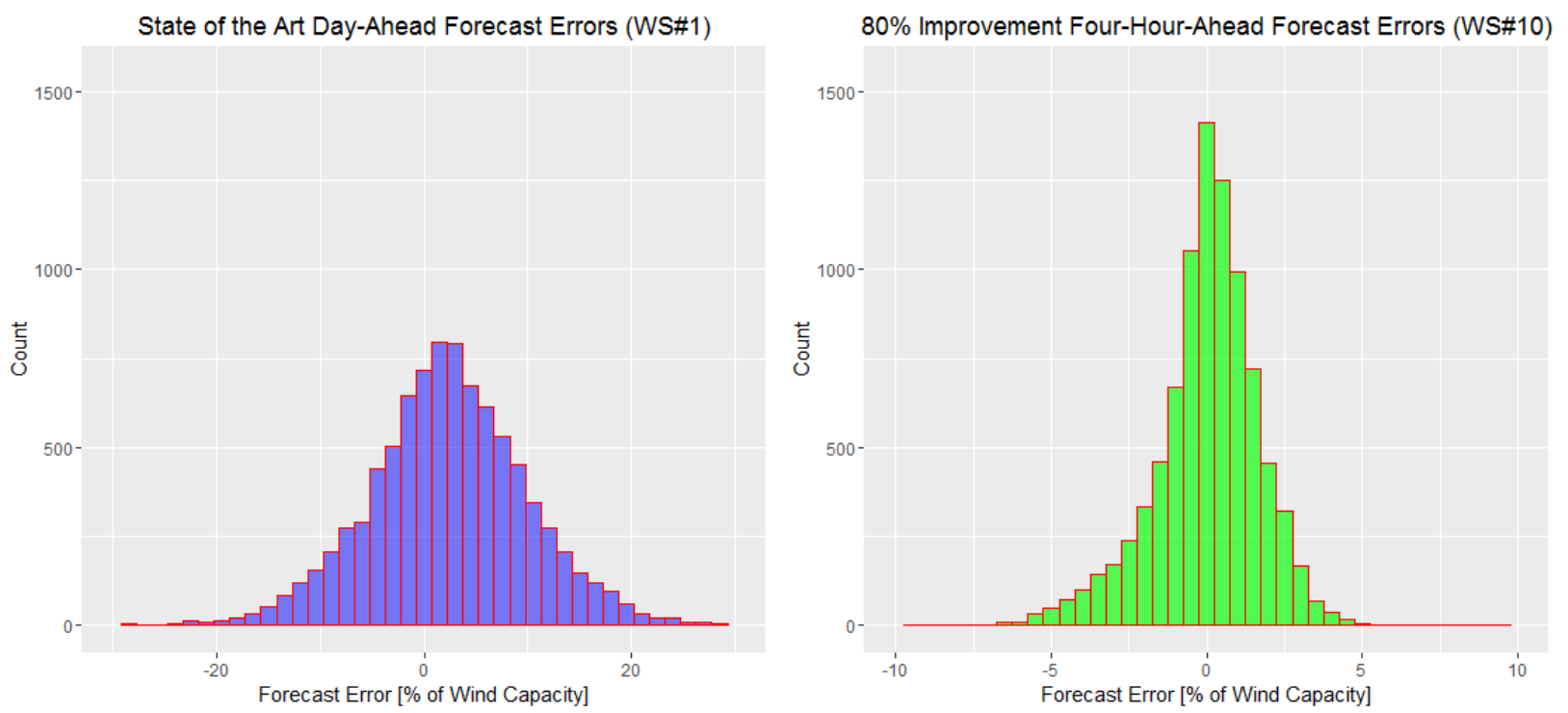

Fig. 1. Distributions of day-ahead and 4HA wind power forecasting errors for, respectively, the extreme cases: wind scenarios (WS) with the least (\#1) and greatest (\#10) amount of installed capacity. In light of these low and high wind penetration scenarios, the juxtaposition of typically large (day-ahead) and small (4HA) forecasting errors illustrates the absolute versus relative trade-offs examined herein. Although normalized by installed wind capacity, shorter forecasting horizons are marked by leptokurtic behavior due to more frequent yet smaller errors.

Three common error metrics [33]-MAE, mean bias error (MBE), and root mean square error (RMSE) - were used to compare the wind power forecasts. Figures 2-4 illustrate the distribution of the bulk MAE, MBE, and RMSE metrics (i.e., calculated annually and additively for each of the 10 wind power plants) as normalized by installed wind capacity for each level of wind forecasting improvement for all 10 scenarios. Each bin of the box plot contains the MAE, MBE, and RMSE metric for each scenario, i.e., 10 per bin. It is interesting to note that the $4 \mathrm{HA}$ box plots show more variability in this statistic; however, the error is less. 
1

2

3

4

5

6

7

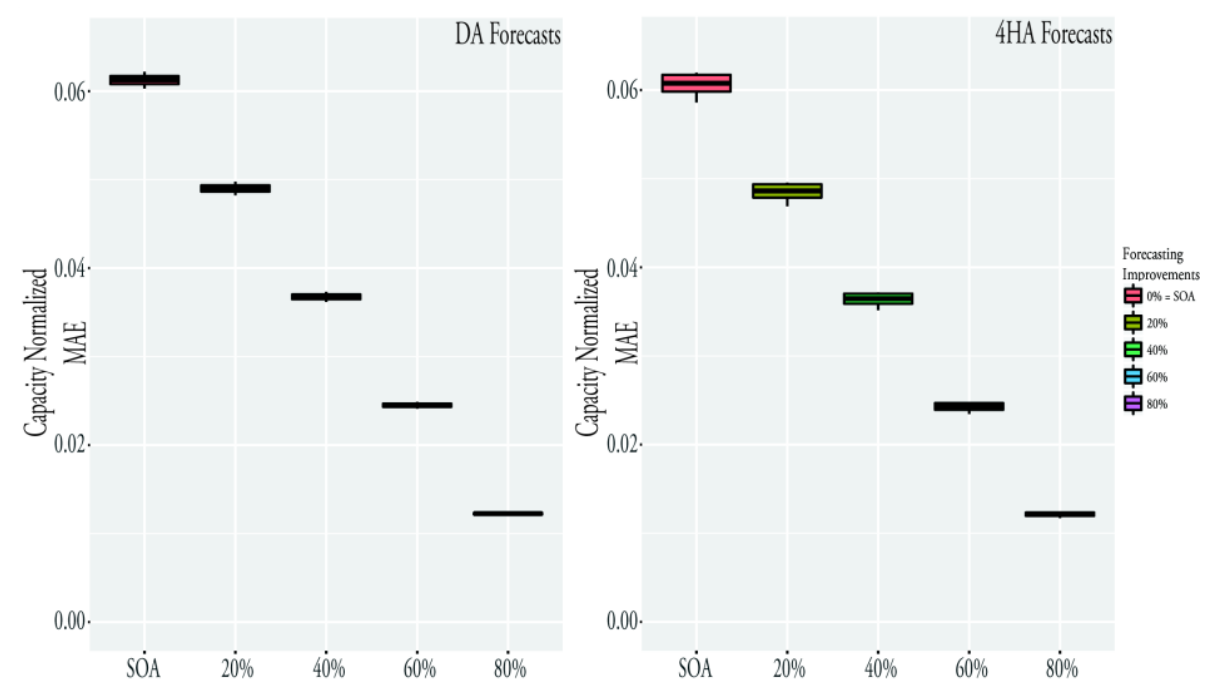

Fig. 2. Box plots of day-ahead and 4HA forecasting error metrics as normalized by installed wind capacity: average bulk MAE statistics (i.e., calculated annually with 10 scenarios per bin).

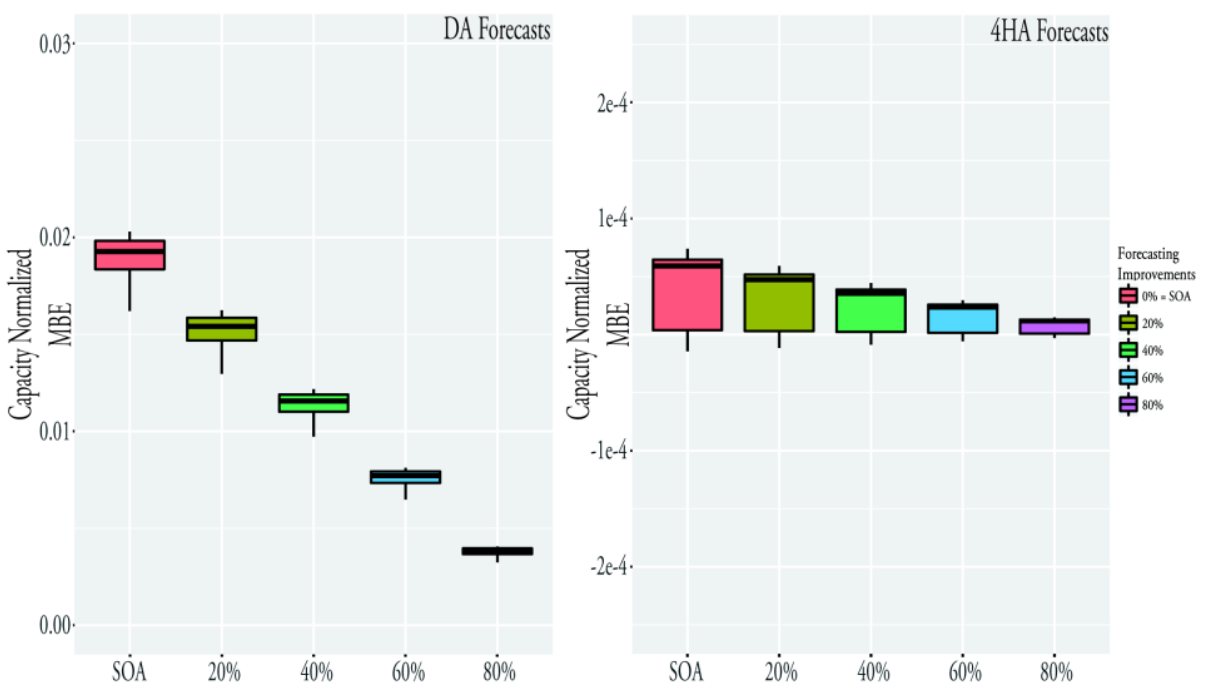

Fig. 3. Box plots of day-ahead and 4HA forecasting error metrics as normalized by installed wind capacity: average bulk MBE statistics (i.e., calculated annually with 10 scenarios per bin). 


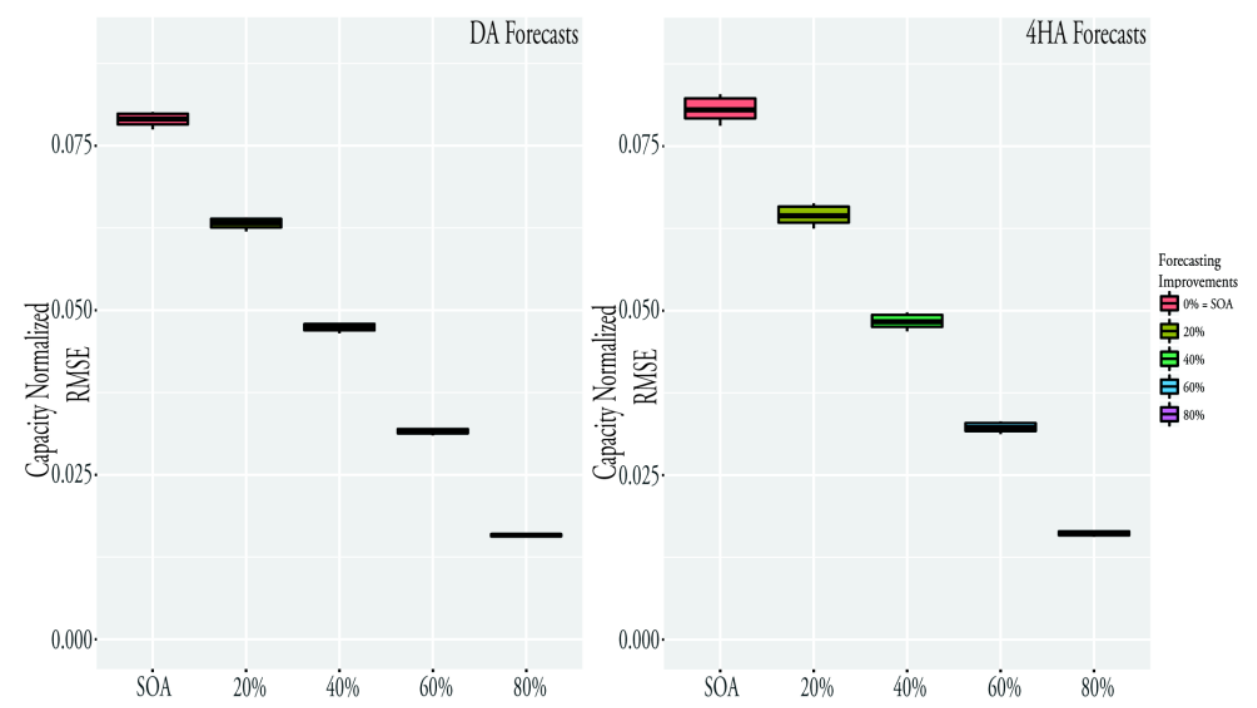

Fig. 4. Box plots of day-ahead and 4HA forecasting error metrics as normalized by installed wind capacity: average bulk RMSE statistics (i.e., calculated annually with 10 scenarios per bin).

Figure 5 shows the real-time, actual wind power output for Scenario \#5 (27.69\% wind penetration level), and five wind power forecasting improvement scenarios at the day-ahead timescale for a typical week from August 27 to September 2, 168 hours in total. The day-ahead forecasts are based on Weather Research and Forecasting forecasts in the WIND Toolkit [34]. In what follows, the $0 \%$ improvement curve corresponds to the state-of-the-art Weather Research and Forecasting model, whereas the $100 \%$ improvement curve (not shown in Figure 5) is identical to the real-time, actual wind power curve. Figure 5 shows that in some intervals the day-ahead wind power is over-forecasted (the red line is above the black line); whereas in other intervals the day-ahead wind power is under-forecasted (the red line is below the black line).

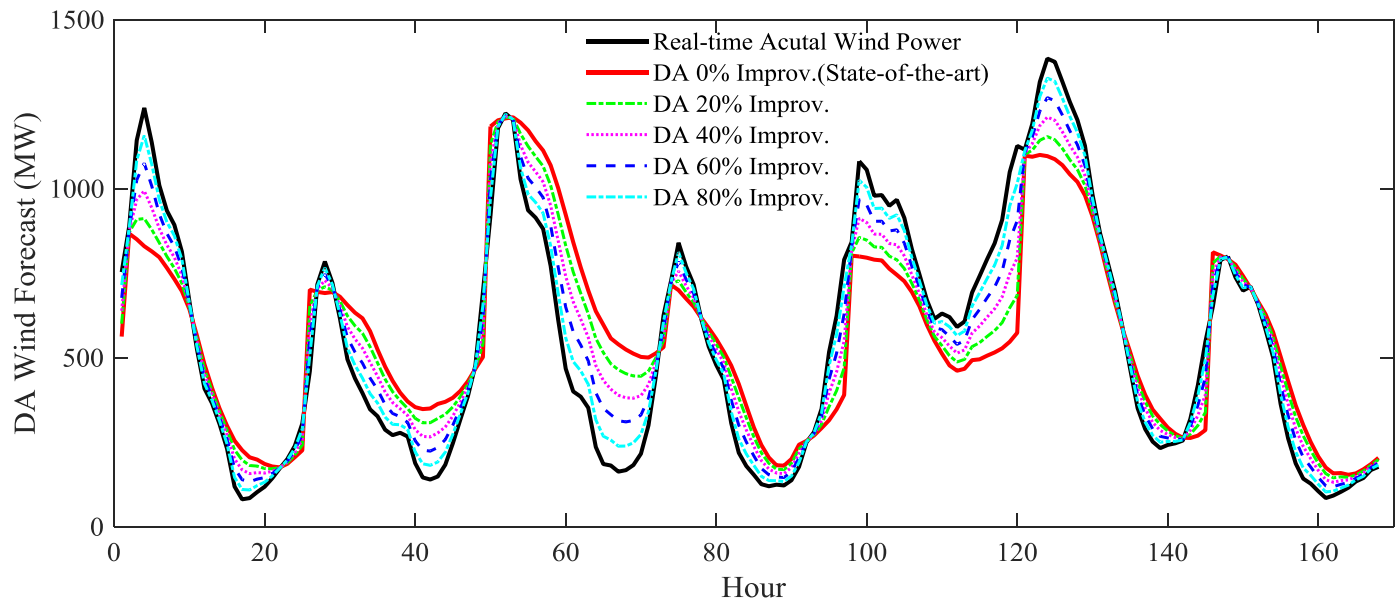

Fig. 5. Example of the day-ahead wind power forecasting improvements

\section{Scenario Design and Production Cost Modeling}


The value of wind power forecasting is related to many different factors. The key factors we examine are forecast timescale, wind penetration rate, and market structure. It is only by examining the interplay among these aspects that we can begin to estimate the value of wind power forecasting improvements in a particular region. In this study, instead of simulating an actual bulk grid, we conducted the design of the scenarios on a modified IEEE 118-bus system to emulate the generation mixes of three different BAAs. The benefits of designing the experiments in this manner are numerous. 1) It enables us to simulate all the scenarios within an acceptable amount of time. According to our scenario design, we have 10 wind penetration levels for each of the three BAAs and 6 wind power forecasting improvement scenarios. For each simulation, we need to conduct three runs: day-ahead forecast improvement only, 4HA forecast improvement only, and both day-ahead and 4HA forecast improvement. Thus, there are a total of 480 runs, each performing a production cost simulation during 1 full year. Based on our previous experience, a typical 1-year simulation takes approximately 2 days on the ISO-NE bulk system [35], and it takes approximately 1 week on the Western Electricity Coordinating Council (WECC) system [36]. It would thus be time prohibitive to conduct the total 480 runs on an actual system such as ISO-NE or WECC. For our modified 118-bus system, it takes approximately 8 hours for a typical run. The total 480 runs thus required approximately 3,840 hours. 2) Because we plan to compare the cost reduction rates in systems with similar generation mixes, changing only the generation mix while leaving all other parameters, the same provides a clearer comparison. Otherwise, various transmission, generation, meteorological, and operational aspects would change from one case to another, diminishing the ability to make a fair comparison and ascribe cost implications to forecasting improvements. Simulating representations of three different actual BAAs would not enable us to achieve this goal because economic impacts could be the result of transmission congestion, interchange limits, operational practices, or any number of other factors that differ among BAAs.

\subsection{Scenario Design to Emulate Three BAAs}

The current generation resource mix data from CAISO, MISO, and ISO-NE are used for the base case simulations in the study. The percentages of energy and capacity for different kinds of generations in the three ISOs are shown in Table 1. The values are modified from the 2014 market reports of CAISO [37], ISO-NE [38], and MISO [30], respectively. The original data in CAISO and ISO-NE have $28 \%$ and $16.3 \%$ net imported energy, respectively. Because we model an isolated power system in this study, the imported energy is removed, and the percentages for all other generation types are recalculated accordingly. The total generation capacity remains the same for three base cases: 7,220 MW, which is the generation capacity of the original IEEE 118bus system. Table 1 shows that the MISO market is dominated by coal, whereas the CAISO and ISO-NE markets are dominated by natural gas (NG in tables). The CAISO market has relatively higher wind and solar capacities, whereas the ISO-NE market has relatively lower wind and solar capacities. Currently, MISO has approximately 7\% wind energy and close to $0 \%$ solar energy. Pumped-storage (PS in tables) generators are modeled in the ISO-NE cases. The pump efficiency is set to a reasonable assumed value $(75 \%)$ in the simulation. 
Table 1.

Generation data in the three base cases in terms of both energy capacity (\%) and energy (\%)

\begin{tabular}{r|r|r|r|r|r|r}
\hline \multirow{2}{*}{$\begin{array}{r}\text { Generation } \\
\text { Mix }\end{array}$} & \multicolumn{2}{|c|}{ CAISO } & \multicolumn{2}{c|}{ ISO-NE } & \multicolumn{2}{c}{ MISO } \\
\cline { 2 - 7 } & Bapase Case & \multicolumn{2}{c}{ Base Case } & \multicolumn{2}{c}{ Base Case } \\
\hline Wind & 10 & \multicolumn{1}{c|}{ Energy (\%) } & Capacity (\%) & Energy (\%) & Capacity (\%) & Energy (\%) \\
\hline Hydro & 14.4 & 6.9 & 3.5 & 1.8 & 14.9 & 7.0 \\
\hline Solar & 6 & 6.7 & 14.3 & 6.6 & - & - \\
\hline Geothermal & 2.4 & 7.2 & - & 0.3 & - & - \\
\hline Biomass & 1.7 & 3.4 & 3.5 & 6.9 & 2.1 & 3.9 \\
\hline NG & 60.9 & 57.7 & 44 & 44.8 & 40.0 & 7.6 \\
\hline Coal & 0.7 & 0.5 & 6 & 5.1 & 35.8 & 67.4 \\
\hline Nuclear & 3.3 & 9.7 & 13 & 33.7 & 4.7 & 13.9 \\
\hline Oil & 0.6 & .01 & 11.7 & 0.004 & 2.5 & 0.2 \\
\hline PS Gen & - & - & 3 & 0.6 & - & - \\
\hline PS Load & - & - & - & -0.8 & - & - \\
\hline Total & 100 & 100 & 100 & 100 & 100 & 100 \\
\hline
\end{tabular}

Because we plan to compare the cost reduction rates for different wind penetration levels, we fixed all other parameters, except for the wind input data, to simulate different scenarios in each BAA. Table 2 shows the 10 testing scenarios we designed, with annual energy wind penetration levels uniformly changing from $5 \%$ to $50 \%$, as shown in the second column. The only difference in the input data among these scenarios is the wind power; all other input parameters remain the same. However, the generation mix solutions, which are optimized according to the production cost simulation engine, vary in the system generation mix scenarios.

The third column of Table 2 shows the wind penetration levels as input information for each scenario. They are calculated by dividing the total wind power by the total load amount. Note that the input penetration levels are slightly different from the designed penetration levels. The reason is that the wind power data are directly extracted from individual wind sites in the WIND Toolkit, and we do not manipulate (scale up/down) the data. For instance, we design Scenario \#1 to expect a 5\% penetration level; however, it is difficult to find available wind sites that have total outputs exactly equal to $5 \%$ of the annual energy. Instead, we found several wind sites that have total outputs equal to $5.87 \%$ of the annual energy, which is very close to the $5 \%$ designed value. Detailed information on the selected wind sites from the WIND Toolkit is shown in the appendix.

The fourth through sixth columns of Table 2 show the actual wind penetration levels for the three different system cases. They are calculated after the PLEXOS simulations finish. Their values are different from those in Column 3 because of the existence of wind curtailments. Obviously, larger curtailment is induced at high wind penetration scenarios. In addition, the three simulated systems have slightly different values for each scenario because they have different realized generation commitments and dispatches.

For each of the 10 scenarios, we run four tests to measure the effects of improving wind power forecasting at different timescales: current state of the art, day-ahead improvement only, 4HA improvement only, and both day-ahead and 4HA improvements. Table 3 shows a description of each test. Note that in our previous work [28], less simulation runs were conducted because 
comparing the impacts of improved wind power forecasts at different timescales was not the focus, and we ran only the cases with both day-ahead and 4HA improvements.

Table 2.

Different kinds of wind penetration levels: 1) designed penetration level, 2) input penetration level, and 3) actual penetration level after dispatch

\begin{tabular}{c|c|c|c|c|c}
\hline $\begin{array}{c}\text { Scenario } \\
\#\end{array}$ & $\begin{array}{c}\text { Designed Penetration } \\
\text { Level (\%) }\end{array}$ & $\begin{array}{c}\text { Input Penetration } \\
\text { Level }(\%)\end{array}$ & \multicolumn{3}{|c}{ Actual Penetration Level After Dispatch (\%) } \\
\cline { 4 - 5 } & 5 & 5.87 & CAISO & ISO-NE & MISO \\
\hline 1 & 10 & 10.48 & 10.47 & 10.07 & 5.87 \\
\hline 2 & 15 & 15.16 & 15.15 & 14.58 & 15.45 \\
\hline 3 & 21.77 & 21.71 & 20.82 & 21.06 \\
\hline 4 & 25 & 27.69 & 27.38 & 25.95 & 25.89 \\
\hline 5 & 30.53 & 32.16 & 30.19 & 30.00 \\
\hline 6 & 35 & 37.35 & 34.88 & 32.56 & 32.38 \\
\hline 7 & 40 & 41.68 & 37.46 & 34.78 & 34.78 \\
\hline 8 & 45 & 47.66 & 40.61 & 37.34 & 37.65 \\
\hline 9 & 50 & 51.64 & 42.45 & 38.73 & 39.27 \\
\hline 10 & & & &
\end{tabular}

Table 3.

Four tests were run for each scenario

\begin{tabular}{lll}
\hline \multicolumn{1}{c}{ Scenario } & \multicolumn{1}{c}{ Description } \\
\hline Test 1 & State of the Art & $\begin{array}{l}\text { Original case without wind power } \\
\text { forecasting improvements }\end{array}$ \\
\hline Test 2 & DA Only & Improve only the DA forecast \\
\hline Test 3 & 4HA Only & Improve only the 4HA forecast \\
\hline Test 4 & DA \& 4HA & $\begin{array}{l}\text { Improve the DA and 4HA forecasts } \\
\text { simultaneously }\end{array}$ \\
\hline
\end{tabular}

The actual historical load from the San Diego Gas \& Electric (SDG\&E) area in year 2012 was used for the simulations [39]. The 2012 SDG\&E peak load was 4,620 MW, which is close to the maximum load in the original IEEE 118-bus system (4,772.75 MW) [31]. The annual hourly load profile is shown in Figure 6. The parameters for traditional generators are obtained from the WECC Transmission Expansion Planning Policy Committee (TEPPC) 2024 Common Case database [40]. The average fuel costs for natural gas, biomass, coal, nuclear, geothermal, and oil plants are set to \$5.24/MMBTU, \$2.68/MMBTU, \$1.99/MMBTU, \$0.81/MMBTU, $\$ 0 / \mathrm{MMBTU}$, and $\$ 20.96 / \mathrm{MMBTU}$, respectively. These values are calculated by averaging the actual data from the database. The production cost, which is calculated by the product of fuel cost and heat rate, is a quadratic curve for each individual generator. We can obtain the average production costs of different generation technologies with the simulation results for each case. In addition, all the resources have additional unit-specified variable O\&M costs. The proportions of regulating-up, regulating-down, and spinning reserves are set to $1 \%, 1 \%$, and $3 \%$ of the system load, respectively. Note that different systems may have different criteria to determine the exact values, but the ones we use here are reasonable for electricity market analysis [41]. Ten wind generators were placed on bus numbers 4, 26, 27, 40, 49, 62, 89, 100, 107, and 112 of the original IEEE 118-bus system [28]. 


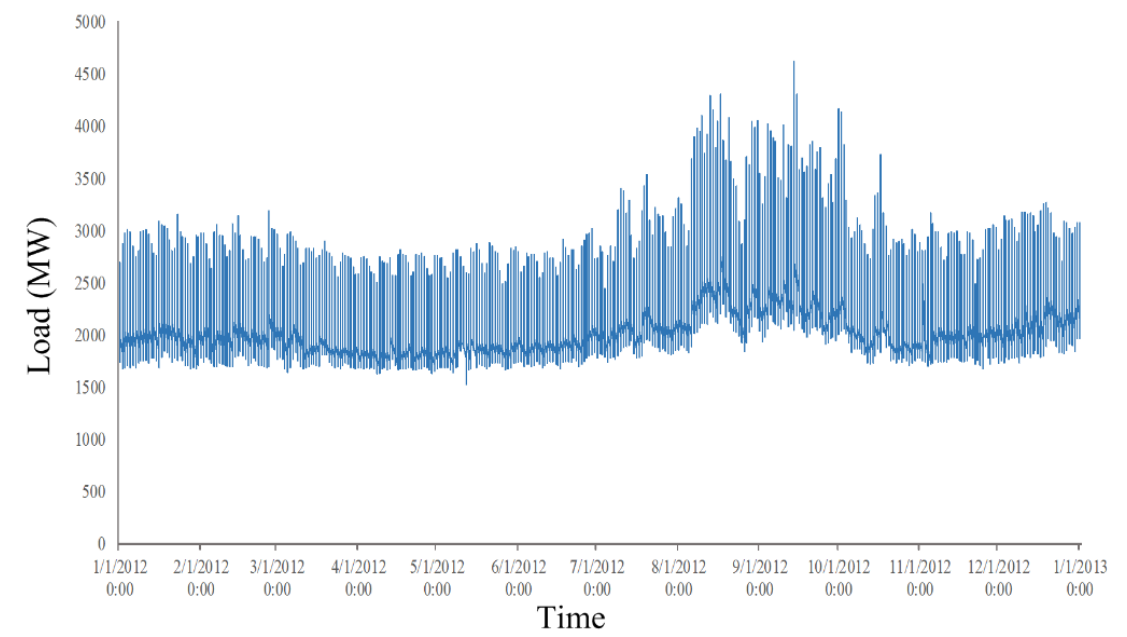

Fig. 6. 2012 annual load profile in SDG\&E area

\subsection{Production Cost Simulation}

The commercial production cost software PLEXOS [42] is the simulation tool utilized for this study. PLEXOS is an electricity market simulation tool that uses mathematical programming and advanced optimization techniques to provide a comprehensive analytical framework for power system modeling. The model can simulate the operation and locational marginal pricing [43] of wholesale electricity markets in a way that is similar to many independent system operator/regional transmission organization market applications, but it incorporates a much longer simulation time frame [44].

Within the production cost simulation model, we run the market by co-optimizing energy and reserves at three timescales: day-ahead, 4HA, and real time (RT in tables). The day-ahead market determines the hourly unit commitments for the 24 hours of the next day. The 4HA market is designed to recommit fast-ramping resources to meet the forecasted net load variations, wherein the net load equals the actual system load minus the renewable generations. The real-time market balances the real-time load and generation in the system. Different power generators have different unit commitment scheduling decisions in the market depending on their unique start-up and shutdown times. Some types of units must be committed 1 day ahead or earlier (e.g., biomass, coal, nuclear, and geothermal), other types of units instead can be recommitted 4 hours ahead (e.g., gas combined cycle, gas and oil steam turbines), and others may be recommitted 1 hour ahead or less (e.g., gas and oil fast turbines and internal combustion engines). Hydro units are typically flexible and are often used for supplying peak generations. In our simulation, the hydro units are committed 1 day-ahead, and they are allowed to be freely dispatched in $4 \mathrm{HA}$ and real time. Pumped-storage units are allowed to be re-dispatched in real time.

The proposed simulation process runs in a sequential operating mode as follows. 1) The process starts with taking long-term hydro constraints and decomposing them into daily constraints using the PLEXOS medium-term schedule function. Based on the available hydro energy, the mediumterm schedule simulates the long-term system operations using load duration curves and produces short-term hydro budget constraints for the daily modeling. 2) The day-ahead market simulation is then performed for an entire year to generate hourly unit commitment and dispatch decisions. The day-ahead forecasted wind and load profiles are used in this stage of the 
simulation. 3) The 4HA simulation starts with fixed unit commitment results for non-fast ramping units passed from the day-ahead solution. 4) The real-time process starts with fixed unit commitment results passed from the day-ahead and 4HA, and it dispatches the available units to meet the load as well as to allow for the recommitment of gas and oil fast turbines and combustion turbines. In all the unit commitment models, the mixed-integer linear programming (MILP) optimality gap is set to $0.1 \%$. In PLEXOS, the unit commitment is a MILP problem and is solved using a linear-programming-based branch-and-bound algorithm, and the MILP gap is the relative difference between the current upper and lower bounds in the solving process [45]. Although many independent system operators currently operate subhourly energy markets, in this study we adopted an hourly real-time market for the modeling. For the variables we examined, such as generation mixes and overall generation production costs, hourly real-time markets produce very similar results to subhourly markets [46].

\section{Study Results and Analysis}

The annual production cost modeling results of the 480 simulated scenarios were analyzed in terms of total generation production costs, wind power curtailment, and electricity generation and ramping of conventional generators. The state-of-the-art forecast cases (i.e., $0 \%$ wind power forecasting improvement) are used as the benchmarks. Then we compare them to cases where only the day-ahead forecast is improved, cases where only the 4HA forecast is improved, and cases where both the day-ahead and 4HA forecasts are improved simultaneously.

\subsection{Base Case Simulation Results}

The base cases are designed to have generation energy mixes similar to those of the current CAISO, ISO-NE and MISO electricity markets, as shown in Table 1 . The load and network data in the three base cases are kept the same. The only difference is the generation mix diversity. Figure 7 shows the generation stacks for the three base cases from September 14 to September 15 , which are the peak load days of the year. It is observed that the CAISO case is dominated by natural gas, the ISO-NE case is dominated by natural gas and nuclear, and the MISO case is dominated by coal. The CAISO case has higher renewable energy penetrations than the MISO and ISO-NE cases. The annual real-time production costs of CAISO, ISO-NE, and MISO cases in the year 2012 are $\$ 722.15 \mathrm{M}, \$ 768.50 \mathrm{M}$, and $\$ 676.07 \mathrm{M}$, respectively. These values are the PLEXOS simulation results for the three base cases. Note that these would not be the actual production costs of the three actual independent system operators because we are simulating a smaller load system; they represent the production costs with systems that have the same load profile as SDG\&E but different generation mixes to resemble the CAISO, ISO-NE, and MISO markets. The production cost in the CAISO base case is smaller than that in ISO-NE base case because the latter has more nuclear energy while the former has more renewable energy, which has a low marginal cost. The production cost in the MISO base case is the lowest because it is dominated by the relatively cheaper coal resource. 

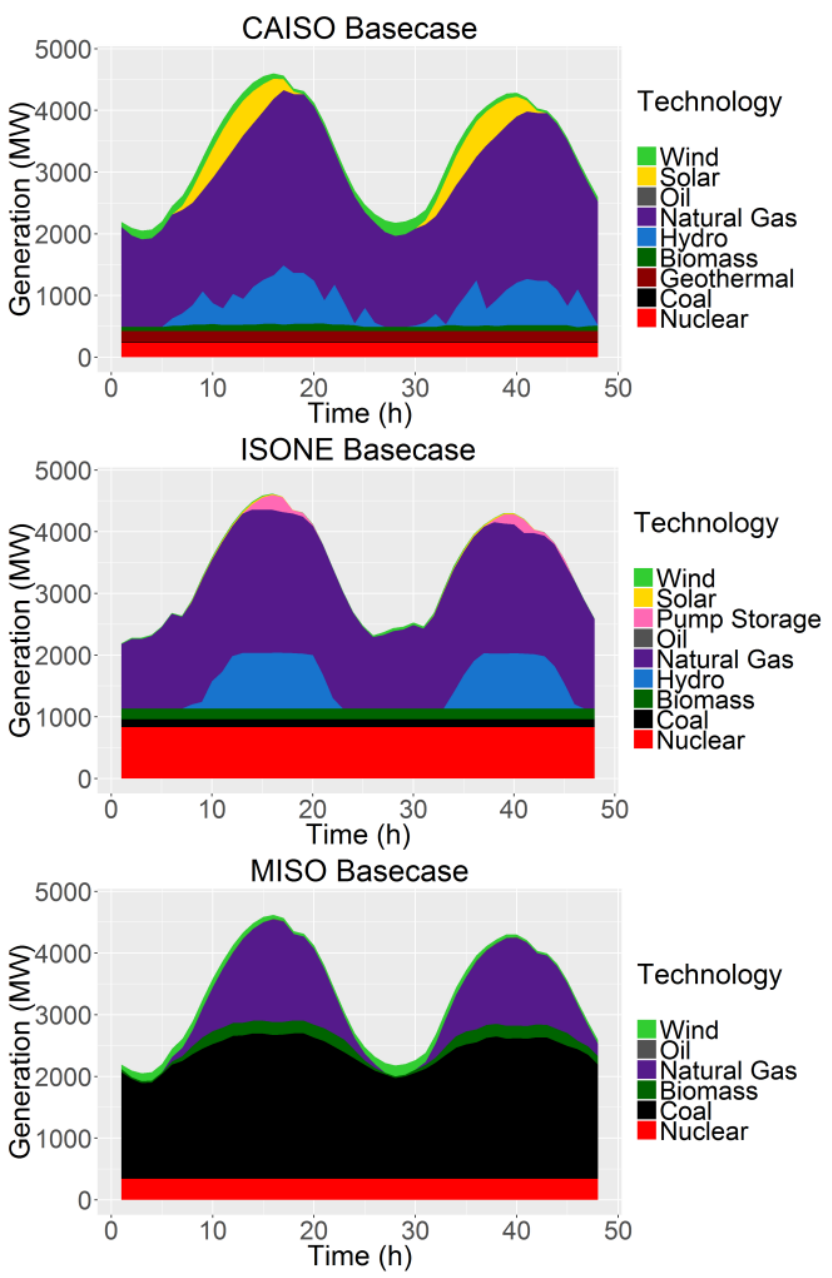

Fig. 7. Generation stacks for peak load days September 14, 2012-September 15, 2012 (48 hours): (a) CAISO base case; (b) ISO-NE base case, and (c) MISO base case

With the high penetration of renewable energy sources and the increased variability and uncertainty of system net loads, operational flexibility has become an important property of modern electric grids. Reference [47] reviews the energy system flexibility measures to enable high levels of variable renewable electricity such as pumped hydro storage and demand-side management. Reference [48] examines the feasibility of integrating large-scale wind power into the Brazilian northeast subsystem, which has a high proportion of hydroelectricity. Reference [49] establishes the necessary framework to quantify the power system operational flexibility via a few metrics such as the power ramp rate, power and energy capability of generators, and loads and storage devices. Comparing the operational flexibility of the three simulated systems will give additional insights for the analysis. As shown in [50], a number of key factors impact grid flexibility. The mix of generation technologies in the system is one of the most important considerations. For example, a system dominated by natural gas will likely have a higher level of flexibility than a system dominated by coal or nuclear generators. The ramp rate ranges of all generation sources that are available to follow the variations in net load are another important consideration. Another factor is the percentage of must-run base-load generators (which should always be committed in the system), a high penetration of which may reduce grid flexibility. The existence of spatial diversity, shiftable load, and energy storage in the grid are other imporant 
factors. In this study, the flexiblity of the three different system generation mix scenarios are compared through the following factors: the percentage of must-run base-load generations (i.e., nuclear power generation), the diversity of generation technologies, and the normalized total available ramp rate and minimum generation levels. Table 4 shows the total available ramp rate, total minimum generation level, number of units, and total capacity of different generation technologies in the three generation mix scenarios. The total available ramp rate and minimun generation levels are calculated by summing the ramp rate and minimum generation values of the individual units, which are obtained from the WECC TEPPC database and have the same order of magnitude as those in reference [47]. An analysis of the operational flexiblility of the three systems is shown as follows:

- A major must-run base-load generation resource - nuclear power in the CAISO, ISO-NE, and MISO base cases - accounts for $9.7 \%, 33.7 \%$, and $13.9 \%$, respectively, of the total energy according to Table 1; hence, the ISO-NE system is relatively less flexible in terms of the "must-run" metric.

- Generation mix is a basic feature of a system. Table 4 shows that the CAISO (MISO) system has the most (least) diversified generation technologies. In addition, a coaldominated system is generally less flexible than a gas-dominated system because coal power plants usually have longer minimum run times once started [28]. As shown in Table 1, the MISO system is dominated by coal (67.4\%), whereas the CAISO and ISONE systems are dominated by natural gas $(57.7 \%$ and $44.8 \%$, respectively). Thus, the MISO system is less flexible than the CAISO and ISO-NE systems in terms of generation mix diversity and flexibility.

- The total capacity of different generation technologies varies in Table 4. To make a fair comparison, we need to normalize the capacities into an equal value - for example, 1,000 MW. We use the natural gas in the CAISO base case as an example. The normalized total available ramp capability is calculated as $(76.93 / 4395) \times 1,000=17.50 \mathrm{MW} / \mathrm{min}$, which means that the total available ramp capability for a $1,000-\mathrm{MW}$ natural gas generator is 17.5 MW per minute. Similary, normalized total available ramp capability and normalized total minimum generation levels for the dominant generation resources are calculated, as shown in Table 5. Normally, coal plants have slower ramp rates and higher minimun generation levels (thus less flexibility) than natural gas plants [49]. This is shown in the MISO base case in Table 5, wherein the coal plants have a smaller ramp capability and larger minimum generation values than the natural gas plants. When we look at the dominant resources in the three systems, ${ }^{3}$ the coal plants in MISO have a smaller normalized total available ramp capability value than the natural gas plants in CAISO and ISO-NE. On the other hand, the natural gas plants in the CAISO system have the largest normalized total minimum generation level among the three. There are two reasons for this: 1) Although a coal plant normally has a higher minimum generation level than a natural gas plant, it is not guaranteed that this is always true for every single generator. 2) The number of generators selected from the WECC TEPPC database is not large enough (25 natural gas generators in CAISO compared to 20 coal generators in MISO). Further, the natural gas units in CAISO can be shut down if necessary. However, here we compare only the static flexibility of the three systems, thus shutting down the

\footnotetext{
${ }^{3}$ Although the MISO base case has a large capacity of natural gas plants, the natural gas is not the dominated resource because only $7.6 \%$ of energy is produced by natural gas plants, as shown in Table 1 . The MISO base case is dominated by coal, which produces $67.4 \%$ of the energy.
}

Page | 14 
natural gas units is not considered. Instead, it is considered in the analysis below, where dynamic flexibility is compared. Based on the values of the two metrics shown in Table 5, we can compare the operational flexibility of the three systems as follows: 1) the MISO base case is less flexible than the ISO-NE base case; and 2) it is hard to conclude if the MISO base case is less flexible than the CAISO base case or not.

The metrics above demonstrate different factors that contribute to a power system's flexibility. Although it is easy to compare the systems from a single metric, it is difficult to tell which system is more flexible when considering all the metrics together. Although the CAISO base case has a larger normalized total minimum generation level, we may still deem that it has relatively more flexibility than the other two independent system operators because it performs well in all other metrics, including must-run generation, normalized total available ramp capability, and the diversity of the generation technologies. The flexibilities in the ISO-NE and MISO base cases are lower because the former has a larger nuclear percentage, and the latter is dominated by coal.

Table 4.

The total avaialbe ramp capability (MW/min), total minimum generation level (MW), number of units, and total capacity (MW) information for CAISO, ISO-NE and MISO base cases

\begin{tabular}{|c|c|c|c|c|c|c|c|c|c|c|c|c|}
\hline & \multicolumn{4}{|c|}{ CAISO } & \multicolumn{4}{|c|}{ ISO-NE } & \multicolumn{4}{|c|}{ MISO } \\
\hline & $\begin{array}{r}\text { Total } \\
\text { Ramp }\end{array}$ & Min Gen & $\begin{array}{c}\text { Unit } \\
\text { No. }\end{array}$ & $\begin{array}{r}\text { Total } \\
\text { Capacity }\end{array}$ & $\begin{array}{r}\text { Total } \\
\text { Ramp }\end{array}$ & $\begin{array}{l}\text { Min } \\
\text { Gen }\end{array}$ & $\begin{array}{c}\text { Unit } \\
\text { No. }\end{array}$ & $\begin{array}{r}\text { Total } \\
\text { Capacity }\end{array}$ & $\begin{array}{r}\text { Total } \\
\text { Ramp }\end{array}$ & Min Gen & $\begin{array}{l}\text { Unit } \\
\text { No. }\end{array}$ & $\begin{array}{r}\text { Total } \\
\text { Capacity }\end{array}$ \\
\hline Hydro & 10.00 & 0.00 & 4 & 1035 & 10.00 & 0.00 & 4 & 1035 & - & - & - & 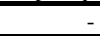 \\
\hline NG & 76.93 & $2,201.37$ & 25 & 4395 & 51.65 & 930.61 & 20 & 3162 & 54.82 & 651.00 & 17 & 2915 \\
\hline Nuclear & 0.00 & 0.00 & 1 & 238 & 0.00 & 0.00 & 2 & 834 & 0 & 0 & 1 & 341 \\
\hline Coal & 4.33 & 44.84 & 2 & 52 & 2.20 & 82.56 & 3 & 155 & 35.17 & $1,173.39$ & 20 & 2551 \\
\hline Oil & 3.40 & 12.89 & 2 & 43 & 12.77 & 135.24 & 9 & 451 & 5.67 & 54.90 & 3 & 183 \\
\hline Biomass & 2.90 & 43.09 & 7 & 121 & 1.66 & 26.77 & 4 & 131 & 1.25 & 38.40 & 3 & 153 \\
\hline Geothermal & 3.15 & 87.80 & 3 & 176 & - & - & - & - & - & - & - & 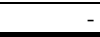 \\
\hline
\end{tabular}

Table 5

Normalized total available ramp capability and normalized total minimum generation level for the dominated generation resources for the CAISO, ISO-NE and MISO base cases

\begin{tabular}{c|c|c|c}
\hline $\begin{array}{c}\text { Base } \\
\text { Case }\end{array}$ & Resource & $\begin{array}{c}\text { Normalized Total Available } \\
\text { Ramp Capability (MW/min) }\end{array}$ & $\begin{array}{c}\text { Normalized Total Minimum } \\
\text { Generation Level (MW) }\end{array}$ \\
\hline CAISO & NG & 17.50 & 500.88 \\
\hline ISO-NE & NG & 16.33 & 294.31 \\
\hline MISO & Coal & 13.78 & 459.98 \\
\hline MISO & NG & 18.81 & 223.33 \\
\hline
\end{tabular}

The three factors presented above are static metrics to measure the flexibility of a power system. After the dispatch solutions are obtained, we can calculate the dynamic flexibility of the system, which is measured by the upward and downward ramp capacity during a specific time period. The upward ramp capacity, or the headroom of a unit at interval $t$, is shown in (1). Similarly, the downward ramp capacity of the unit is shown in (2).

$$
\begin{aligned}
& \text { Ramp Up Capacity }(t)=\min \left\{D M A X_{t}-D_{t}, \operatorname{Ramp}_{t} \times T\right\} \\
& \text { Ramp Down Capacity }(t)=\min \left\{\operatorname{Ramp}_{t} \times T, D_{t}-D_{M I N}\right\}
\end{aligned}
$$


where $D M A X_{t}$ and $D M I N_{t}$ are the maximum and minimum capacity of the unit, $D_{t}$ is the energy dispatch (MW) of the unit at interval $t, \operatorname{Ramp}_{t}$ is the ramp rate of the unit at interval $t$, and $T$ is the number of minutes in interval $t$. For example, $T$ equals 60 minutes for the hourly-dispatch market. The system's overall upward/downward ramp capacity is calculated by the summation of the ramp-up/ramp-down capacity of each committed unit. As shown in Section 3.2, three types of units are based on their commitment timescales: those committed in the day-ahead that pass the commitment to 4HA and real time (e.g., slow-start units such as coal), those committed in the 4HA that pass the commitment to real time (e.g., medium-start units such as combined-cycle plants), and those committed in real time (e.g., fast-start units such as oil and gas combustion turbines). Specifically, coal units are committed in the day-ahead and the 4HA, and the real-time commitment status is fixed as the day-ahead status; combined-cycle units are committed in the 4HA, and the real-time commitment status is fixed as the 4HA status; and oil and combustion turbine units can be freely committed in real time. Figure 8 illustrates the upward/downward ramp capacity of the three kinds of units as well as the system's overall up/down capacity in the week from September 10, 2012-September 16, 2012, which is the peak load week of the year. The results presented here are based on the solution of the base cases for the three independent system operators. It is observed that the ISO-NE base case has the largest upward/downward ramp capacities; however, the upward ramp capacities of the real-time committed units for the ISO-NE base case are close to 0 (as shown in the second figure), which means that all the faststart units are dispatched at their maximum generation levels.
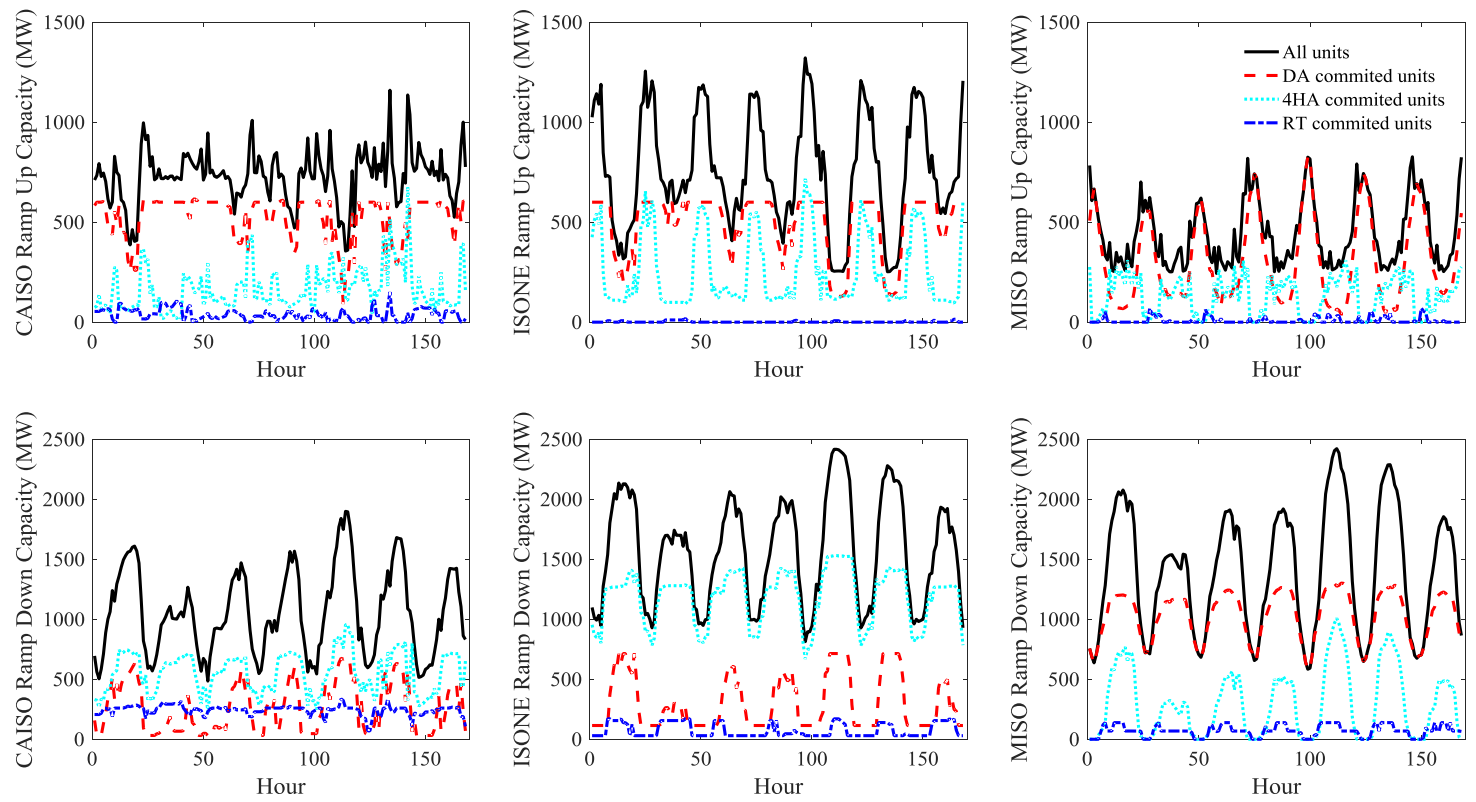

Fig. 8. Dynamic upward and downward ramp capacity for peak load week September 10, 2012-September 16, 2012 (168 hrs)

As shown in Figure 8, the upward ramp capacity in MISO is primarily provided by units committed in the day-ahead, whereas ISO-NE has very little upward ramp capacity provided by the real-time committed units. The downward ramp capacities in the CAISO and ISO-NE cases are mainly provided by units committed in the 4HA, whereas the MISO case mainly relies on day-ahead committed units to provide downward ramp capacity. 


\subsection{Wind Power Forecasting Improvement Scenarios}

Consistent with Table 2, 10 different wind penetration scenarios were simulated for each of the three independent system operators, with six wind power forecasting improvement runs for each scenario $(0 \%, 20 \%, 40 \%, 60 \%, 80 \%$, and $100 \%)$. For each scenario at a certain wind power forecasting improvement level, we conducted three 1-year production cost modeling runs: improving the forecast at day-ahead only, at 4HA only, and at day-ahead and 4HA simultaneously. We calculated the real-time generation production costs savings in millions of dollars $(\$ \mathrm{M})$ due to improved wind power forecasting compared to the benchmark (i.e., the $0 \%$ improvement) case. To reduce redundancy, in Figure 9 we demonstrate only the results for scenarios \#2, \#4, \#6, and \#10, which correspond to approximately $10 \%, 20 \%, 30 \%$, and $50 \%$ of the designed wind penetration levels, respectively. Note that the actual wind penetration levels (the last three columns in Table 2) for these scenarios were approximately 10\%, 20\%, 30\%, and $40 \%$, respectively. The generation production costs value details for the three independent system operators in Scenario \#10 are shown in Figure 10. Table 6 shows the percentages of realtime total generation production costs reduction (\%) compared to the state-of-the-art wind power forecasting for Scenario \#7. For example, a $40 \%$ wind power forecasting improvement in only 4HA will reduce the cost by $1.59 \%$ for the CAISO Scenario \#7, whereas the same amount of wind power forecasting improvement in both 4HA and day-ahead will reduce the cost by $2.34 \%$. The following observations are made from Figure 9, Figure 10, and Table 6:

- The dollar amount of cost reduction increases with improved wind power forecasting. This is more obvious when the wind penetration level is high. It was observed that the curves do not always increase with higher wind power forecasting improvements when the wind penetration level is low (e.g., CAISO Scenario \#2). This is because the MILP gap is set to $0.1 \%$ in the simulations, and the differences are within the MILP gap. In addition, when the wind penetration is low, the system has sufficient flexibility to economically deal with the wind variations.

- Improving the day-ahead and 4HA wind power forecasting simultaneously will bring the largest amount of cost reductions, higher than improving the forecast solely in the dayahead or 4HA; however, it is difficult to make a general conclusion about which timescale is more beneficial to improve forecasting because it depends on various factors, such as the generation mix, grid flexibility, energy storage, and the relative value of grid reliability. In this study, improving wind power 4HA forecasting will lead to larger cost reductions in the CAISO and MISO cases. In contrast, improving day-ahead forecasting is more economically beneficial in the ISO-NE cases. The reasons for this are analyzed in detail in the following sections. 

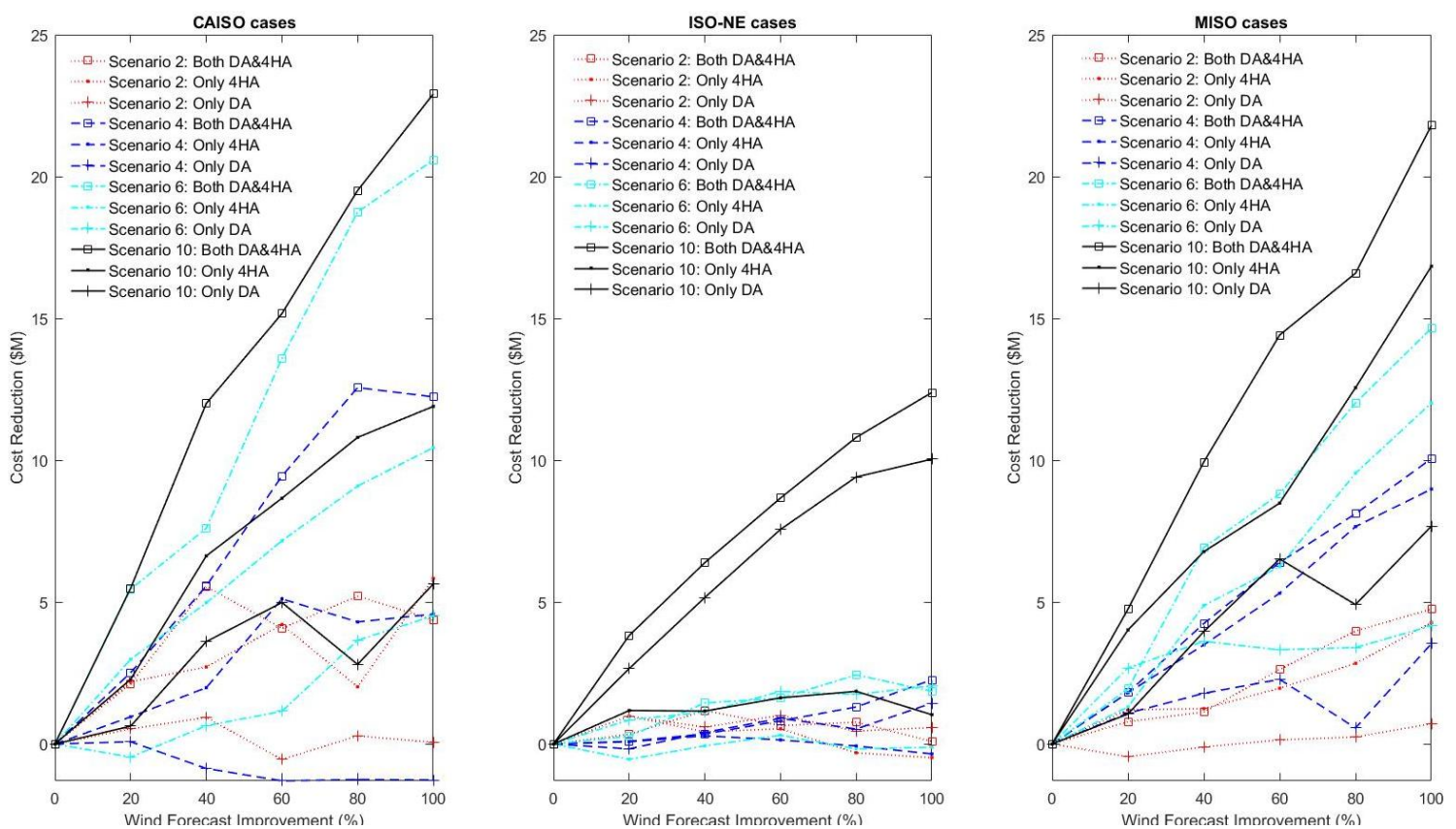

Fig. 9. Cost reductions with wind power forecasting improvements in scenarios \#2, \#4, \#6, and \#10
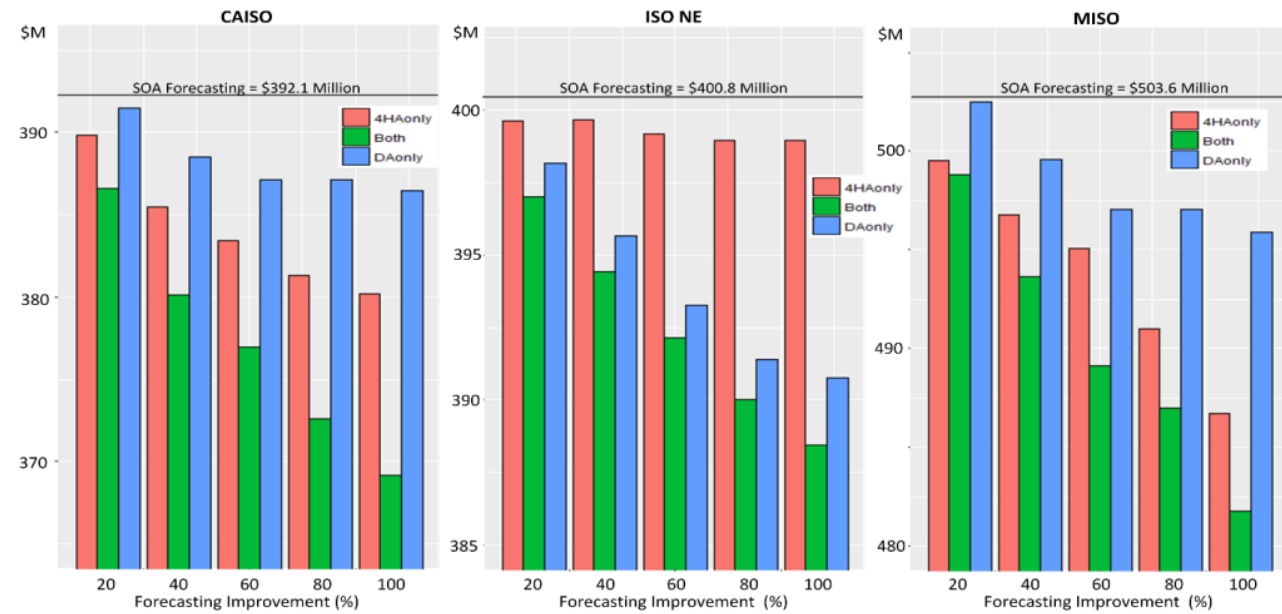

Fig. 10. Cost comparisons in three independent system operators in Scenario \#10 (\$M)

Table 6.

Percentages of real-time total generation production costs reduction (\%) with improved wind power forecasting compared to the state-of-the-art case for Scenario \#7

\begin{tabular}{c|c|c|c|c|c|c}
\hline \multicolumn{2}{c|}{ Scenarios } & \multicolumn{5}{c}{ Wind Forecast Improvement (\%) } \\
\cline { 2 - 7 } \multicolumn{2}{|c|}{} & 20 & 40 & 60 & 80 & 100 \\
\hline \hline \multirow{2}{*}{$\begin{array}{c}\text { CAISO } \\
\text { Scenario \#7 }\end{array}$} & DA Only & 0.23 & 0.29 & 0.55 & 0.57 & 0.58 \\
\cline { 2 - 7 } & 4HA Only & 0.91 & 1.59 & 1.87 & 2.15 & 2.24 \\
\cline { 2 - 7 } & DA \& 4HA & 1.21 & 2.34 & 3.24 & 3.96 & 4.47 \\
\hline \multirow{2}{*}{ ISO-NE } & DA Only & 0.13 & 0.47 & 0.78 & 0.82 & 0.91 \\
\cline { 2 - 7 } Scenario \#7 & 4HA Only & 0.09 & 0.14 & 0.25 & 0.28 & 0.31 \\
\cline { 2 - 7 } & DA \& 4HA & 0.22 & 0.72 & 1.00 & 1.02 & 1.03 \\
\hline \multirow{2}{*}{ MISO Scenario } & DA Only & 0.24 & 0.52 & 1.03 & 1.07 & 1.19 \\
\cline { 2 - 7 }$\# 7$ & 4HA Only & 0.66 & 1.16 & 1.42 & 1.95 & 2.39 \\
\cline { 2 - 7 } & DA \& 4HA & 0.54 & 1.21 & 2.15 & 2.71 & 3.49 \\
\hline
\end{tabular}


Table 7.

Average production costs of different generation technologies for Scenario \#7 base cases $(\$ / \mathrm{MWh})$

\begin{tabular}{r|r|r|r}
\hline $\begin{array}{r}\text { Generation } \\
\text { Technologies }\end{array}$ & $\begin{array}{c}\text { CAISO Scenario \#7 } \\
\text { Base Case }\end{array}$ & $\begin{array}{c}\text { ISO-NE Scenario \#7 } \\
\text { Base Case }\end{array}$ & $\begin{array}{c}\text { MISO Scenario \#7 } \\
\text { Base Case }\end{array}$ \\
\hline NG & 56.41 & 56.42 & 79.36 \\
\hline Nuclear & 23.04 & 23.04 & 23.04 \\
\hline Coal & 38.97 & 31.72 & 33.42 \\
\hline Biomass & 21.38 & 37.30 & 34.73 \\
\hline Oil & 199.57 & 208.44 & 248.00 \\
\hline Geothermal & 2.92 & - & - \\
\hline
\end{tabular}

5

In Section 3.1, we mentioned that the average production costs of different generation technologies can be obtained from the simulation results, and the value varies in different simulation cases. To provide more insights for future analysis, we calculate the average production costs of different generation technologies for the Scenario \#7 base cases in the different generation mix scenarios, as shown in Table 7. As shown, oil generation is the most expensive, and natural gas is more expensive than nuclear, coal, and biomass generation.

Table 8 shows the cost savings per MWh of wind power generation with wind power forecasting improvement in the Scenario \#7 cases. The values are calculated by dividing the annual cost savings ( $\$$ ) by the total wind generation $(\mathrm{MWh})$. Consider CAISO Scenario \#7. In the base case, the total operational generation cost, total generation, and total wind generation is $\$ 464.85 \mathrm{M}$, 20,054.98 GWh, and 7,511.81 GWh, respectively. For the "DA Only" case, with 40\% wind power forecast improvement, those values are $\$ 463.51 \mathrm{M}, 20,055.01 \mathrm{GWh}$, and 7,510.45 $\mathrm{GWh}$, respectively. For the "4HA Only" case, with $40 \%$ wind power forecasting improvement, those values are $\$ 457.46 \mathrm{M}, 20,054.98 \mathrm{GWh}$, and 7,517.87 GWh, respectively. For the "DA \& 4HA" case, with $40 \%$ wind power forecasting improvement, those values are $\$ 453.99 \mathrm{M}, 20,054.98$ GWh, and 7,530.06 GWh, respectively. Compared to the base case, a $40 \%$ wind power forecasting improvement reduces annual operational electricity generation production costs by $\$ 1.34 \mathrm{M}$ (=\$464.85M-\$463.51M), \$7.39M, and \$10.86M, respectively, for the CAISO "DA Only," "4HA Only," and "DA \& 4HA" cases. Dividing the cost savings by the total wind generation, we obtain the equivalent average savings per $\mathrm{MWh}$ of wind power generation, $\$ 0.18$ $(=\$ 1.34 \mathrm{M} / 7510.45 \mathrm{GWh}), \$ 0.98$, and $\$ 1.44$, respectively, for those cases. To the authors' best knowledge, this is the first attempt in literature to quantify the cost savings from wind power forecasting improvement per unit of wind power generation. Reference [51] indicated that the wind integration costs were approximately $\$ 2 / \mathrm{MWh}$ at a $15 \%$ penetration level and $\$ 4 / \mathrm{MWh}$ at a $25 \%$ penetration level; however, it did not quantify the cost savings due to wind power forecasting improvements. Reference [27] provided the total production cost saving from an improved wind power forecast, but it did not calculate the cost savings per unit of wind power. Reference [26] calculated the production cost savings per unit of solar power, wherein the values 
varied from $\$ 0.11 / \mathrm{MWh}$ to $\$ 1.42 / \mathrm{MWh}$. The order of magnitude of the values in references [51] and [26] are consistent with the results shown in Table 8.

Table 8.

Cost savings per MWh of wind power generation from improved wind power forecasting for the Scenario \#7 cases (\$/MWh)

\begin{tabular}{c|c|c|c|c|c|c}
\hline \multirow{2}{*}{ Scenarios } & \multicolumn{5}{c}{ Wind Forecast Improvement $(\%)$} \\
\cline { 3 - 7 } & DA Only & 20 & 40 & 60 & 80 & 100 \\
\hline \multirow{3}{*}{$\begin{array}{c}\text { CAISO } \\
\text { Scenario \#7 }\end{array}$} & 4HA Only & 0.14 & 0.18 & 0.34 & 0.35 & 0.34 \\
\cline { 2 - 7 } & DA \& 4HA & 0.75 & 1.44 & 2 & 2.44 & 2.75 \\
\hline \multirow{2}{*}{$\begin{array}{c}\text { ISO-NE } \\
\text { Scenario \#7 }\end{array}$} & DA Only & 0.08 & 0.29 & 0.48 & 0.48 & 0.56 \\
\cline { 2 - 7 } & 4HA only & 0.06 & 0.08 & 0.15 & 0.15 & 0.15 \\
\cline { 2 - 7 } & DA \& 4HA & 0.13 & 0.45 & 0.62 & 0.63 & 0.63 \\
\hline \multirow{2}{*}{$\begin{array}{c}\text { MISO Scenario } \\
\text { \#7 }\end{array}$} & DA Only & 0.18 & 0.4 & 0.79 & 0.79 & 0.92 \\
\cline { 2 - 7 } & 4HA Only & 0.41 & 0.89 & 1.1 & 1.51 & 1.84 \\
\cline { 2 - 7 } & DA \& 4HA & 0.42 & 0.93 & 1.66 & 2.09 & 2.69 \\
\hline
\end{tabular}

To understand why improving the day-ahead wind power forecasting leads to higher economic benefits in the ISO-NE case, whereas improving the 4HA wind power forecasting leads to higher economic benefits in the CAISO and MISO cases, we need to decompose the total generation production costs by generation resource types. To reduce redundancy, we select only one case for analysis: Scenario \#9, with $40 \%$ wind power forecasting improvement. For other cases, the conclusions are similar. The decompositions of energy and total generation production costs by resource type for the CAISO, ISO-NE, and MISO systems are shown in Table 9, Table 10, and Table 11, respectively. The total production costs for hydro, wind, solar, and pumped-storage generations are assumed to be zero because they have no fuel costs and their marginal O\&M costs are assumed to be zero in the simulation. In reality, those resources should have non-zero total O\&M costs; however, this is a common assumption in production cost modeling based on their bidding behavior in market environments. The total production cost includes three parts: unit start-up and shutdown cost, fuel cost, and O\&M cost. The O\&M cost is relatively low compared to the other two. To avoid redundancy, only total production costs are listed in Table 9-Table 11. The below conclusions can be generalized from those results:

- In a coal-dominated system (e.g., MISO), improving the day-ahead wind power forecasting will utilize more coal resources than improving the 4HA wind power forecasting by the same amount. In a natural-gas-dominated system (e.g., ISO-NE), improving the day-ahead wind power forecasting will utilize less natural gas resources than improving the $4 \mathrm{HA}$ wind power forecasting by the same amount. This is because coal plants are generally less flexible than natural gas plants, with longer start-up and shutdown times. For the MISO case, improving the day-ahead wind power forecasting will have a more significant impact to the generation of coal plants. For the ISO-NE case, improving the $4 \mathrm{HA}$ wind power forecasting will have greater impacts on the generation 
of more flexible natural gas plants. On the other hand, we observed that although the CAISO case was also dominated by natural gas, the generation from natural gas plants was very close between improving the day-ahead and 4HA wind power forecasting (5,935.2 GWh compared to 5,935.9 GWh, respectively). This was because the percentage of natural gas resources is higher in CAISO than it is in ISO-NE. For example, in the ISO-NE system, the generation from nuclear plants (which were simulated as must-run units) was more than two times that of natural gas generation, whereas in the CAISO system the generation from nuclear plants was much lower; thus, the CAISO system has more available natural gas units to meet the uncertainty brought by improving wind power forecasting at different timescales, which makes the energy generated by natural gas units very close in the improvements of the "DA Only" and "4HA Only" cases, as shown in Table 9.

- The dominated non-base-load resources in the system have the most significant impact on the total generation production costs. For instance, comparing the "DA Only" to the "4HA only" columns in Table 10, the total generation production costs for coal, oil, biomass, and pumped-storage generation resources is lower in the latter, but the total generation production costs for natural gas (which is the dominated non-base-load resource) is significantly higher. This makes the annual generation production costs when improving only the $4 \mathrm{HA}$ wind power forecasting higher than when improving only the day-ahead wind power forecasting. In addition, Table 9 shows that although the energy output from natural gas in the "DA Only" and "4HA only" cases is very close, the total production cost of natural gas generation is quite different. The reason is that different types of natural gas units have different operational efficiencies-e.g., combined-cycle natural gas plants are more efficient than open-cycle natural gas plants. In the "DA only" case, more open-cycle natural gas plants are dispatched; thus, the production cost is higher.

.
Decomposition of energy and total generation production costs by resource type for CAISO Scenario \#9, with 40\%
wind power forecasting improvement

\begin{tabular}{|c|c|c|c|c|c|c|}
\hline & \multicolumn{2}{|c|}{ DA Only } & \multicolumn{2}{|c|}{ 4HA Only } & \multicolumn{2}{|c|}{ DA \& 4HA } \\
\hline Generation Type & Energy (GWh) & $\begin{array}{l}\text { Total Production } \\
\text { Cost }(\$ \mathrm{k})\end{array}$ & Energy (GWh) & $\begin{array}{l}\text { Total Production } \\
\text { Cost }(\$ \mathrm{k})\end{array}$ & Energy $(\mathrm{GWh})$ & $\begin{array}{l}\text { Total Production } \\
\text { Cost }(\$ \mathrm{k})\end{array}$ \\
\hline Hydro & $1,478.3$ & 0.0 & $1,475.0$ & 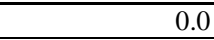 & $1,478.3$ & 0.0 \\
\hline NG & $5,935.2$ & $339,870.2$ & $5,935.9$ & $336,549.2$ & $5,906.5$ & $331,880.4$ \\
\hline Nuclear & $2,088.7$ & $48,135.2$ & $2,088.7$ & $48,135.2$ & $2,088.7$ & $48,135.2$ \\
\hline Coal & 75.0 & $2,983.9$ & 75.2 & $2,989.0$ & 75.2 & $2,989.3$ \\
\hline Wind & $8,755.9$ & 0.0 & $8,768.4$ & 0.0 & $8,782.4$ & 0.0 \\
\hline Oil & 3.1 & $1,839.9$ & 3.4 & $1,996.3$ & 3.2 & $1,874.8$ \\
\hline Biomass & 448.3 & $9,933.4$ & 435.8 & $9,470.8$ & 446.6 & $9,851.8$ \\
\hline Geothermal & $1,270.6$ & $3,704.0$ & $1,272.6$ & $3,709.9$ & $1,274.2$ & $3,714.7$ \\
\hline Solar & $1,527.7$ & 0 & $1,527.7$ & 0 & $1,527.7$ & 0 \\
\hline Sum & $21,582.8$ & $406,466.6$ & $21,582.7$ & $402,850.4$ & $21,582.8$ & $398,446.2$ \\
\hline
\end{tabular}


Table 10.

Decomposition of energy and total generation production costs by resource type for ISO-NE Scenario \#9, with 40\% wind power forecasting improvement

\begin{tabular}{|c|c|c|c|c|c|c|}
\hline & \multicolumn{2}{|c|}{ DA Only } & \multicolumn{2}{|c|}{ 4HA Only } & \multicolumn{2}{|c|}{ DA \& 4HA } \\
\hline Generation Type & Energy $(\mathrm{GWh})$ & $\begin{array}{l}\text { Total Production } \\
\text { Cost }(\$ \mathrm{k})\end{array}$ & Energy (GWh) & $\begin{array}{l}\text { Total Production } \\
\text { Cost }(\$ \mathrm{k})\end{array}$ & Energy (GWh) & $\begin{array}{l}\text { Total Production } \\
\text { Cost }(\$ \mathrm{k})\end{array}$ \\
\hline Hydro & $1,346.0$ & 0.0 & $1,316.0$ & 0.0 & $1,344.7$ & 0.0 \\
\hline NG & $3,257.2$ & $188,293.8$ & $3,330.8$ & $192,833.5$ & 3262.2 & $187,870.8$ \\
\hline Nuclear & $7,331.5$ & $168,953.4$ & $7,331.2$ & $168,953.4$ & 7331.5 & $168,953.4$ \\
\hline Coal & 595.4 & $19,195.7$ & 573.0 & $18,433.3$ & 586.8 & $18,856.5$ \\
\hline Wind & $8,372.8$ & 0.0 & $8,364.2$ & 0.0 & 8375.2 & 0.0 \\
\hline Oil & 3.2 & $1,365.9$ & 2.3 & $1,037.1$ & 1.9 & 834.3 \\
\hline Biomass & 790.5 & $29,942.6$ & 778.3 & $29,545.8$ & 791.4 & $29,991.6$ \\
\hline Solar & 62.9 & 0 & 62.9 & 0 & 62.9 & 0 \\
\hline PS Gen & 594.9 & 0 & 583.1 & 0 & 585.4 & 0 \\
\hline Sum & $22,354.4$ & $407,751.4$ & $22,341.8$ & $410,803.1$ & 22,342 & $406,506.6$ \\
\hline
\end{tabular}

Table 11.

Decomposition of energy and total generation production costs by resource type for MISO Scenario \#9, with 40\% wind power forecasting improvement

\begin{tabular}{|c|c|c|c|c|c|c|}
\hline & \multicolumn{2}{|c|}{ DA Only } & \multicolumn{2}{|c|}{ 4HA Only } & \multicolumn{2}{|c|}{ DA \& 4HA } \\
\hline Generation Type & Energy (GWh) & $\begin{array}{l}\text { Total Production } \\
\text { Cost }(\$ \mathrm{k})\end{array}$ & Energy (GWh) & $\begin{array}{l}\text { Total Production } \\
\text { Cost }(\$ \mathrm{k})\end{array}$ & Energy $(\mathrm{GWh})$ & $\begin{array}{l}\text { Total Production } \\
\text { Cost }(\$ \mathrm{k})\end{array}$ \\
\hline NG & $1,812.5$ & $137,130.6$ & $1,983.6$ & $141,609.1$ & $1,853.3$ & $134,033.3$ \\
\hline Nuclear & $2,993.2$ & $68,977.9$ & $2,993.2$ & $68,977.9$ & $2,993.2$ & $68,977.9$ \\
\hline Coal & $8,057.6$ & $273,518.4$ & $7,886.6$ & $266,633.8$ & $8,006.5$ & $271,135.3$ \\
\hline Wind & $8,086.8$ & 0 & $8,122.8$ & 0.0 & $8,108.4$ & 0.0 \\
\hline Oil & 17.6176 & $9,504.8$ & 15.4 & $8,561.2$ & 15.4 & $8,390.5$ \\
\hline Biomass & 566 & 19,334 & 533.1 & $18,108.8$ & 556.9 & $18,915.8$ \\
\hline Sum & $21,533.7$ & $508,465.7$ & $21,534.7$ & $503,890.8$ & $21,533.7$ & $501,452.8$ \\
\hline
\end{tabular}

Wind power forecasting improvements at different operational timescales will impact real-time wind curtailment in the system. Table 12 shows the annual wind power curtailment changes for CAISO Scenario \#9. Wind power curtailment $(\mathrm{GWh})$ in the state-of-the-art case is used for benchmarking. In the state-of-the-art case, the actual wind power generation is $8,744.03 \mathrm{GWh}$, the curtailed wind is $1,519.19 \mathrm{GWh}$, and thus the curtailment rate is $14.8 \%$. The average locational marginal price of the case is $\$ 32 / \mathrm{MWh}$; thus, the lost value of the curtailed wind is approximately $\$ 48.6 \mathrm{M}$. Table 12 shows that the percentage that wind power curtailment was reduced (relative to the state-of-the-art case) increased with improved forecasts. For this case, improving the day-ahead and 4HA wind power forecasting simultaneously will bring in the highest curtailment reductions, whereas improving the 4HA wind power forecasting will lead to higher curtailment reductions than improving only the day-ahead wind power forecasting. As a reference, Table 13 shows the wind power curtailments at different penetration levels for the three generation mix scenarios, wherein values are demonstrated for the state-of-the-art cases and for the $40 \%$ wind power forecasting improvement at both day-ahead and 4HA cases. 
Table 12.

Reduction of wind power curtailment (\%) relative to the state-of-the-art case for the CAISO Scenario \#9 cases

\begin{tabular}{c|c|c|c|c|c}
\hline Curtailment & \multicolumn{5}{|c}{ Wind Power Forecasting Improvement } \\
\cline { 2 - 6 } Reduction (\%) & $20 \%$ & $40 \%$ & $60 \%$ & $80 \%$ & $100 \%$ \\
\hline \hline DA Only & 0.7 & 0.8 & 1.1 & 1.4 & 1.6 \\
\hline 4HA Only & 0.8 & 1.6 & 2.0 & 2.0 & 2.3 \\
\hline DA \& 4HA & 1.5 & 2.5 & 3.8 & 4.0 & 5.4 \\
\hline
\end{tabular}

Table 13.

Wind power curtailments for the three simulated systems at different penetration levels: curtailment at state-of-theart case compared to the case of $40 \%$ forecast improvement

\begin{tabular}{|c|c|c|c|c|c|c|c|}
\hline & & \multicolumn{2}{|c|}{ CAISO } & \multicolumn{2}{|c|}{ ISO-NE } & \multicolumn{2}{|c|}{ MISO } \\
\hline $\begin{array}{l}\text { Scena } \\
\text { rio \# }\end{array}$ & $\begin{array}{l}\text { Wind } \\
\text { Level }\end{array}$ & $\begin{array}{c}\text { Curtailment } \\
\text { State-of-the-Art, } \\
\text { GWh }(\%)^{1}\end{array}$ & $\begin{array}{c}\text { Curtailment } \\
\text { 40\% Improve., } \\
\text { GWh }(\%)\end{array}$ & $\begin{array}{c}\text { Curtailment } \\
\text { State-of-the-Art, } \\
\text { GWh }(\%)\end{array}$ & $\begin{array}{c}\text { Curtailment } \\
40 \% \text { Improve., } \\
\text { GWh }(\%)\end{array}$ & $\begin{array}{c}\text { Curtailment } \\
\text { State-of-the-Art, } \\
\text { GWh }(\%)\end{array}$ & $\begin{array}{c}\text { Curtailment } 40 \% \\
\text { Improve., } \\
\text { GWh }(\%)\end{array}$ \\
\hline 2 & $10 \%$ & $\begin{array}{c}0.27 \\
(0.01 \%)\end{array}$ & $\begin{array}{c}0.26 \\
(0.01 \%)\end{array}$ & $\begin{array}{c}0 \\
(0 \%)\end{array}$ & $\begin{array}{c}0 \\
(0 \%) \\
\end{array}$ & $\begin{array}{c}6.06 \\
(0.27 \%)\end{array}$ & $\begin{array}{c}5.81 \\
(0.26 \%)\end{array}$ \\
\hline 4 & $20 \%$ & $\begin{array}{c}12.78 \\
(0.27 \%)\end{array}$ & $\begin{array}{c}12.68 \\
(0.27 \%)\end{array}$ & $\begin{array}{c}25.07 \\
(0.53 \%)\end{array}$ & $\begin{array}{c}24.8 \\
(0.52 \%)\end{array}$ & $\begin{array}{c}151.27 \\
(3.23 \%)\end{array}$ & $\begin{array}{c}150.15 \\
(3.21 \%)\end{array}$ \\
\hline 6 & $30 \%$ & $\begin{array}{c}294.26 \\
(4.08 \%)\end{array}$ & $\begin{array}{c}279.78 \\
(3.88 \%)\end{array}$ & $\begin{array}{c}460.68 \\
(6.38 \%)\end{array}$ & $\begin{array}{l}452.39 \\
(6.27 \%)\end{array}$ & $\begin{array}{c}759.32 \\
(10.52 \%)\end{array}$ & $\begin{array}{c}746.61 \\
(10.34 \%)\end{array}$ \\
\hline 8 & $40 \%$ & $\begin{array}{c}907.62 \\
(10.11 \%)\end{array}$ & $\begin{array}{c}872.56 \\
(9.72 \%)\end{array}$ & $\begin{array}{c}1186.07 \\
(13.22 \%)\end{array}$ & $\begin{array}{c}1176.5 \\
(13.11 \%)\end{array}$ & $\begin{array}{c}1484.49 \\
(16.54 \%)\end{array}$ & $\begin{array}{c}1473.58 \\
(16.42 \%)\end{array}$ \\
\hline 10 & $50 \%$ & $\begin{array}{c}1978.92 \\
(17.80 \%)\end{array}$ & $\begin{array}{c}1938.34 \\
(17.43 \%)\end{array}$ & $\begin{array}{c}2446.8 \\
(22.00 \%)\end{array}$ & $\begin{array}{c}2429.8 \\
(21.85 \%)\end{array}$ & $\begin{array}{c}2663.12 \\
(23.95 \%)\end{array}$ & $\begin{array}{c}2651.21 \\
(23.84 \%)\end{array}$ \\
\hline
\end{tabular}

${ }^{1}$ Note: The values outside the brackets are the curtailed wind power in GWh; the values inside the brackets are the percentages of wind curtailment.

\subsection{The Impact of Pumped-Storage Resource}

In the ISO-NE test case, the pumped-storage devices may mitigate variations in system condition and thus reduce the benefits of wind power forecasting improvements. To eliminate the impacts of pumped-storage units on the system, we replaced them with gas turbine units that have the same capacities. All other parameters remained the same, and these new cases were rerun. Two ISO-NE cases were selected for demonstration: Scenario \#3 (low wind penetration) and Scenario \#9 (high wind penetration). Table 14 shows the simulation results of annual production cost savings (\%) with and without pumped-storage units by improving wind power forecasts at different timescales. Note that by replacing the pumped-storage units (results shown in the "Without PS" rows), the production cost saving percentages are higher (compared to the results shown in the "With PS" rows). This confirms that the existence of storage resources in the system can reduce the benefits of wind power forecasting improvements. In addition, in both of the scenarios, improving the day-ahead wind power forecasting can bring higher cost saving rates compared to improving the $4 \mathrm{HA}$ wind power forecasting by the same amount when the pumped-storage resources are replaced. This is because pumped storage is not the dominant resource in the ISO-NE system. The general conclusion that improving the day-ahead wind 
power forecasting is more beneficial than improving the 4HA wind power forecasting for the ISO-NE system remains the same, even when removing the impacts of pumped-storage units.

3

4

5

Table 14.

Comparing the percentage of cost savings $(\%)$ with and without pumped-storage units

\begin{tabular}{|c|c|c|c|c|c|c|c|}
\hline \multirow{2}{*}{ Scenario } & \multirow{2}{*}{ Timescale } & \multirow{2}{*}{ PS Units } & \multicolumn{5}{|c|}{ Wind Power Forecasting Improvement (\%) } \\
\hline & & & 20 & 40 & 60 & 80 & 100 \\
\hline \multirow{6}{*}{$\begin{array}{c}\text { ISO-NE } \\
\text { \#3 }\end{array}$} & \multirow{2}{*}{ DA Only } & With PS & 0.04 & 0.09 & 0.09 & 0.10 & 0.14 \\
\hline & & Without PS & 0.05 & 0.29 & 0.27 & 0.61 & 0.62 \\
\hline & \multirow{2}{*}{ 4HA Only } & With PS & 0.01 & 0.01 & 0.04 & 0.04 & 0.08 \\
\hline & & Without PS & 0.02 & 0.20 & 0.21 & 0.41 & 0.41 \\
\hline & \multirow{2}{*}{$\begin{array}{c}\text { DA and } \\
4 \mathrm{HA}\end{array}$} & With PS & 0.09 & 0.01 & 0.06 & 0.13 & 0.14 \\
\hline & & Without PS & 0.13 & 0.44 & 0.44 & 0.36 & 1.00 \\
\hline \multirow{6}{*}{$\begin{array}{c}\text { ISO-NE } \\
\quad \# 9\end{array}$} & \multirow{2}{*}{ DA Only } & With PS & 0.30 & 0.85 & 1.51 & 1.65 & 1.95 \\
\hline & & Without PS & 0.39 & 1.21 & 1.82 & 2.15 & 2.15 \\
\hline & \multirow{2}{*}{ 4HA Only } & With PS & 0.04 & 0.11 & 0.22 & 0.25 & 0.27 \\
\hline & & Without PS & 0.23 & 0.77 & 0.79 & 1.00 & 1.03 \\
\hline & \multirow{2}{*}{ DA \& 4HA } & With PS & 0.50 & 1.15 & 1.65 & 2.25 & 2.25 \\
\hline & & Without PS & 0.90 & 1.60 & 2.25 & 2.56 & 3.38 \\
\hline
\end{tabular}

Table 15 shows the cost savings (\$) per unit (MWh) of wind power generation by simulating the cases with and without pumped-storage resources, respectively. To give a general concept of the magnitude of the values, we list the actual total operational generation cost (\$), total generation $(\mathrm{GWh})$, and total wind generation $(\mathrm{GWh})$ for the state-of-the-art scenarios with pumped storage. In the ISO-NE Scenario \#3, those values are $\$ 640.4 \mathrm{M}, 21,565.6 \mathrm{GWh}$, and 2,960.5 $\mathrm{GWh}$, respectively. In the ISO-NE Scenario \#9, those values are $\$ 411.2 \mathrm{M}, 21,698.1 \mathrm{GWh}$, and 8,363.2GWh, respectively.

It is observed that the cost savings per unit of wind power generation are higher in the high-wind power penetration scenario. In addition, when the system does not have pumped-storage rsouces, the cost saving per unit of wind power generation is higher than when the system has pumpedstorage resouces - except for the "DA Only" test in the ISO-NE Scenario \#9. This was because improving wind power forecasting at the day-ahead only does not significnatly impact cost reductions for the ISO-NE cases because they do have many day-ahead commited resoruces, such as coal.

Table 15.

Comparing the cost savings per unit of wind power generation with and without pumped-storage units (\$/MWh)

\begin{tabular}{|c|c|c|c|c|c|c|c|}
\hline \multirow{2}{*}{ Scenario } & \multirow{2}{*}{ Timescale } & \multirow{2}{*}{ PS Units } & \multicolumn{5}{|c|}{ Wind Power Forecasting Improvement (\%) } \\
\hline & & & 20 & 40 & 60 & 80 & 100 \\
\hline \multirow{6}{*}{$\begin{array}{c}\text { ISO-NE } \\
\text { \#3 }\end{array}$} & \multirow{2}{*}{ DA Only } & With PS & 0.10 & 0.20 & 0.20 & 0.21 & 0.31 \\
\hline & & Without PS & 0.21 & 0.54 & 0.54 & 0.65 & 0.65 \\
\hline & \multirow{2}{*}{ 4HA Only } & With PS & 0.01 & 0.01 & 0.09 & 0.09 & 0.09 \\
\hline & & Without PS & 0.12 & 0.65 & 0.65 & 1.38 & 1.38 \\
\hline & \multirow{2}{*}{ DA \& 4HA } & With PS & 0.12 & 0.12 & 0.12 & 0.29 & 0.29 \\
\hline & & Without PS & 0.30 & 0.99 & 1.02 & 1.02 & 2.25 \\
\hline
\end{tabular}




\begin{tabular}{c|c|c|c|c|c|c|cc}
\hline \multirow{4}{*}{$\begin{array}{c}\text { ISO-NE } \\
\# 9\end{array}$} & \multirow{2}{*}{ DA Only } & With PS & 0.18 & 0.47 & 0.82 & 0.90 & 1.05 \\
\cline { 3 - 9 } & \multirow{2}{*}{4 HA Only } & Without PS & 0.04 & 0.44 & 0.48 & 0.91 & 0.91 \\
\cline { 3 - 9 } & & With PS & 0.01 & 0.06 & 0.11 & 0.06 & 0.13 \\
\cline { 2 - 9 } & \multirow{2}{*}{ DA \& 4HA } & Without PS & 0.34 & 0.88 & 1.29 & 1.54 & 1.54 \\
\cline { 3 - 9 } & & With PS & 0.26 & 0.64 & 0.90 & 1.22 & 1.22 & 2.27 \\
\hline
\end{tabular}

\subsection{The Impact of Generation Ramp Rate}

The ramp rate refers to the rate at which a power plant can increase or decrease electricity generation within the dispatch interval. As an important indicator of the system flexibility, the system-level ramp-up and ramp-down capacities in generating units are paramount to managing variability in electric loads. The impacts of variable resources on grid operations are perhaps best represented on the duck curve of the CAISO wholesale electricity market, wherein 13,000 MW of ramp capacity is need in 3 hours [26]. To investigate the impacts of ramp-rate constraints on the system, we select the Scenario \#9 base cases for CAISO, ISO-NE, and MISO for analysis. The percentages of production cost reductions are calculated by comparing the original cases to the corresponding cases with ramp-rate constraints relaxed (i.e., setting the ramp rate to a very large number), as shown in Table 16. The ramp rates for all resources are relaxed in the cases, and the minimum generation levels for all resources are kept the same. Generally, relaxing the ramp rate of the coal units will cause higher cost reductions than relaxing the ramp rate of the same quantity of natural gas units in the same system; however, when relaxing different kinds of generators in different systems, the conclusions are not as straightforward. In our test, the ISONE base case has the smallest cost reduction rate because it has a large volume of nuclear power, which serves the base load and normally cannot ramp up and down quickly. The CAISO base case has larger cost reduction rate than the MISO base case, which may be because CAISO has more diversified generation technologies, and if the ramp-rate limits for all units are relaxed, the dispatch engine can select more cost-effective resources to meet the load, and thus the production cost is much lower.

Table 17 compares the percentages of production cost savings to wind power forecasting improvements on the case with a relaxed generation ramp rate. Higher production cost savings are observed with improved wind power forecasts. For the CAISO and MISO cases, improving the 4HA wind power forecasting is more beneficial; whereas for the ISO-NE cases, it is more beneficial to improve the day-ahead forecasts. The conclusion remains the same as in Section 4.2. This indicates that the generation mix of the system, instead of the ramp rate, is the key factor that determines the value of the improved wind power forecast in different timescales for different markets. 
Table 16.

Production costs with and without ramp-rate constraint relaxations

\begin{tabular}{c|c|c|c}
\hline & $\begin{array}{c}\text { Cost Without } \\
\text { Relaxation }\end{array}$ & $\begin{array}{c}\text { Cost With } \\
\text { Relaxation }\end{array}$ & Cost Reduction \\
\hline \hline CAISO \#9 Base Case & $409.92 \mathrm{M}$ & $383.71 \mathrm{M}$ & $6.39 \%$ \\
\hline ISO-NE \#9 Base Case & $411.24 \mathrm{M}$ & $406.10 \mathrm{M}$ & $1.25 \%$ \\
\hline MISO \#9 Base Case & $511.78 \mathrm{M}$ & $501.27 \mathrm{M}$ & $2.05 \%$ \\
\hline
\end{tabular}

Table 17.

Percentage of production cost savings $(\%)$ with relaxed generation ramp rates

\begin{tabular}{c|c|c|c|c|c|c}
\hline \multirow{2}{*}{ Case } & \multirow{2}{*}{ Timescale } & \multicolumn{5}{|c}{ Wind Power Forecasting Improvement (\%) } \\
\cline { 3 - 7 } & & 20 & 40 & 60 & 80 & 100 \\
\hline \hline \multirow{2}{*}{ CAISO } & DA Only & 0.47 & 0.47 & 0.78 & 1.16 & 1.33 \\
\cline { 2 - 7 } \#9 Case & 4HA Only & 0.89 & 1.39 & 2.22 & 2.7 & 2.96 \\
\cline { 2 - 7 } & DA \& 4HA & 1.24 & 2.44 & 4.27 & 4.99 & 5.84 \\
\hline \multirow{2}{*}{ ISO-NE } & DA Only & 0.78 & 1.95 & 2.48 & 3.26 & 3.61 \\
\cline { 2 - 7 } \#9 Case & 4HA Only & 0.54 & 0.54 & 0.98 & 1.2 & 1.21 \\
\cline { 2 - 7 } & DA \& 4HA & 0.88 & 2.17 & 3.32 & 4.12 & 4.79 \\
\hline \multirow{2}{*}{ MISO } & DA Only & 0.27 & 0.58 & 0.65 & 0.88 & 1.01 \\
\cline { 2 - 7 } \#9 Case & 4HA Only & 0.66 & 1.77 & 2.51 & 4.55 & 4.59 \\
\cline { 2 - 7 } & DA \& 4HA & 1.11 & 2.26 & 3.32 & 4.26 \\
\hline
\end{tabular}

\subsection{The Impact of Minimum Generation Level}

In power system operations, the base-load units (typically large nuclear and coal-fired facilities) often supply the same amount of energy around the clock. To follow the diurnal load cycle, many coal units run at minimum generation levels at night and increase output during the day. These units have relatively high minimum generation levels and slow ramp rates. On the other hand, the intermediate and peaking units, which are generally natural gas or oil-fired facilities, have relatively lower minimum generation levels and faster ramp rates, and they can be shut down and started up quickly. In this study, we relax the minimum generation level for all the generators in the three generation mix scenarios. The must-run status of the nuclear plants is not relaxed. By doing this, the MISO base case will be most significantly impacted because it is dominated by coal. The CAISO base case should have the least impact because it is dominated by more flexible natural gas units. The impact to the ISO-NE base case should be between that of the CAISO and MISO base cases because it has a large amount of nuclear power but also a high volume of natural gas resources. This is confirmed by the results shown in Table 18, wherein the cost reduction rates are calculated by relaxing the minimum generation levels in the CAISO, ISO-NE, and MISO Scenario \#9 base cases. By "relaxing the minimum generation levels," we mean setting their values to 0 in all the simulations. Comparing the results shown in Table 16 to those in Table 18, note that relaxing the generation ramp rates constraints can lead to higher cost reductions than relaxing the minimum generation constraints in the CAISO case, whereas relaxing the minimum generation levels in the ISO-NE and MISO cases can result in more system-wide benefits. 
Table 19 compares the production cost saving rates of the three systems at different timescales by relaxing the minimum generation levels. As shown, improving 4HA forecasts can lead to higher production cost savings for the CAISO and MISO cases, whereas improving the dayahead forecast leads lead to higher production cost saving for the ISO-NE case. The overall conclusion remains the same as in Section 4.2.

Table 18.

Production costs with and without relaxed minimum generation levels

\begin{tabular}{c|c|c|c}
\hline & $\begin{array}{c}\text { Cost Without } \\
\text { Relaxation }\end{array}$ & $\begin{array}{c}\text { Cost With } \\
\text { Relaxation }\end{array}$ & Cost Reduction \\
\hline \hline CAISO \#9 Base Case & $409.92 \mathrm{M}$ & $388.96 \mathrm{M}$ & $5.11 \%$ \\
\hline ISO-NE \#9 Base Case & $411.24 \mathrm{M}$ & $384.52 \mathrm{M}$ & $6.50 \%$ \\
\hline MISO \#9 Base Case & $511.78 \mathrm{M}$ & $461.07 \mathrm{M}$ & $9.91 \%$ \\
\hline
\end{tabular}

Table 19.

Percentage of production cost savings (\%) with relaxed minimum generation levels

\begin{tabular}{c|c|c|c|c|c|c}
\hline \multirow{2}{*}{ Case } & \multirow{2}{*}{ Timescale } & \multicolumn{5}{|c}{ Wind Power Forecasting Improvement (\%) } \\
\cline { 3 - 7 } & & 20 & 40 & 60 & 80 & 100 \\
\hline \hline \multirow{2}{*}{ CAISO } & DA Only & 0 & 0.86 & 0.88 & 0.88 & 1.2 \\
\cline { 2 - 7 } \#9 Case & 4HA Only & 0.73 & 1.27 & 1.56 & 1.56 & 1.65 \\
\cline { 2 - 7 } & DA \& 4HA & 0.92 & 1.97 & 3.12 & 3.74 & 3.9 \\
\hline \multirow{2}{*}{ ISO-NE } & DA Only & 0.15 & 0.73 & 1.18 & 1.22 & 1.24 \\
\#9 Case & 4HA Only & 0.12 & 0.37 & 0.7 & 0.7 & 0.74 \\
\cline { 2 - 7 } & DA \& 4HA & 0.35 & 1.1 & 1.62 & 1.76 & 2.01 \\
\hline \multirow{2}{*}{ MISO } & DA Only & 0.28 & 1.06 & 1.11 & 1.6 & 1.66 \\
\cline { 2 - 7 } \#9 Case & 4HA Only & 0.38 & 1.07 & 1.38 & 1.99 & 2.47 \\
\cline { 2 - 7 } & DA \& 4HA & 0.74 & 1.94 & 2.55 & 3.27 & 3.74 \\
\hline
\end{tabular}

\section{Conclusions}

The analysis of the results presented in this paper provides interesting insights regarding the values of improved wind power forecasting at different operational timescales. The values are evaluated by the annual electricity generation production costs as well as the impacts to system operations. A production cost model that runs day-ahead, 4HA, and real-time markets was adopted for the simulation. The tests were conducted on the IEEE 118-bus system as modified to emulate the generation mixes of CAISO, ISO-NE, and MISO. For each independent system operator, 10 scenarios were simulated with the wind penetration level ranging from $5 \%$ to $50 \%$. For each scenario, six uniform wind power forecasting improvement cases were tested. To compare the values of improved wind power forecasting at different timescales, we performed multiple runs by improving only the day-ahead forecasts, only the 4HA forecasts, and both the day-ahead and 4HA forecasts.

The impact of improved wind power forecasting on system operations was analyzed and compared to the state-of-the-art wind power forecasting model. Improving the wind power forecasting decreases the uncertainty of the overall system, thus leading to higher production cost savings; however, improving wind power forecasting at different market operation timescales will have different impacts on the real-time operation of the system. The results analyzed 
through the paper show that the values largely depend on the generation resource mix of the system. For example, in a coal-dominated system such as MISO, improving the day-ahead wind power forecast will make more coal resources to be utilized in real-time operations than improving the $4 \mathrm{HA}$ wind power forecasting by the same amount. This is due to the long start-up and shutdown times associated with coal generators. In a natural-gas dominated system that has a high percentage of inflexible base-load resources (i.e., nuclear), such as ISO-NE, improving the day-ahead wind power forecasting will mean that less natural gas resources are utilized in realtime operations than improving the $4 \mathrm{HA}$ wind power forecasting improvements by the same amount. In a natural-gas dominated system with a low percentage of inflexible base-load resources, such as CAISO, the real-time natural gas energy utilization when improving the dayahead wind power forecast is very close to that when improving the 4HA wind power forecast. This is because natural gas units are generally more flexible in the system and can mitigate the variability of system operation conditions. In addition, our study shows that the system's annual operational electricity generation production costs is mostly impacted by the cost changes of the dominant resources. More coal energy utilized in the system does not necessarily mean that the total electricity generation production costs are lower, especially when coal is the dominant resource. For example, in the MISO cases, although more coal energy was consumed when improving the day-ahead wind power forecast, the total cost is higher than when improving the 4HA forecast because coal is the dominant resource and the production cost of the coal units is higher in the day-ahead forecast than it is in the 4HA. In a natural gas-dominated system such as CAISO, the consumption of natural gas in the "DA Only" and "4HA Only" cases is very similar; however, the electricity generation production costs of the natural gas resources are quite different. This is because although the total natural gas energy consumptions are close, the energy consumed by different types of natural gas units is different. In the improvement of the "4HA Only" case, more combined-cycle natural gas units, which have lower operational production costs, are dispatched. The study also analyzed the changes in wind power curtailments and the impacts of pumped-storage resources. Finally, we used three metrics to compare the flexibility of the simulated systems: the generation mix, the available ramp rate, and the system minimum generation level. It is observed that higher operational flexibility can be achieved by relaxing the ramp-rate and minimum generation constraints, but production costsaving behaviors are similar to the cases when those constraints are not relaxed. In our tests, we did not simultaneously relax the ramp-rate and minimum generation levels, which may change some of the conclusions in this paper.

Future work could continue to conduct the analysis presented in this paper by simulating an actual electric power system. Another interesting topic would be to design an optimal generation mix (under different wind penetration levels) to reduce carbon-dioxide emissions and/or to increase the operational flexibility of the system. In addition, a comprehensive flexibility index can be examined be assigning proper weights to different flexibility indices. We may also test the impact of relaxing both the ramp rates and minimum generation levels on different systems.

\section{Acknowledgments}

This work was supported by the U.S. Department of Energy (DOE) under Contract No. DEAC36-08-GO28308 with the National Renewable Energy Laboratory. The authors would also like to thank Mark Ahlstrom of WindLogics, James Wilczak of the National Oceanic and 
Atmospheric Administration, and Joel Cline and Charlton Clark of DOE for their helpful guidance.

3

4

\section{Appendix}

Figure A.1 provides a map of the latitude and longitude of wind plants utilized in the study. When combined with the wind turbine aggregation approach, Tables A.1 and A.2, it provides complete wind data information for the concerns of scientific reproducibility. Corresponding data are validated and freely available on the Internet [32].

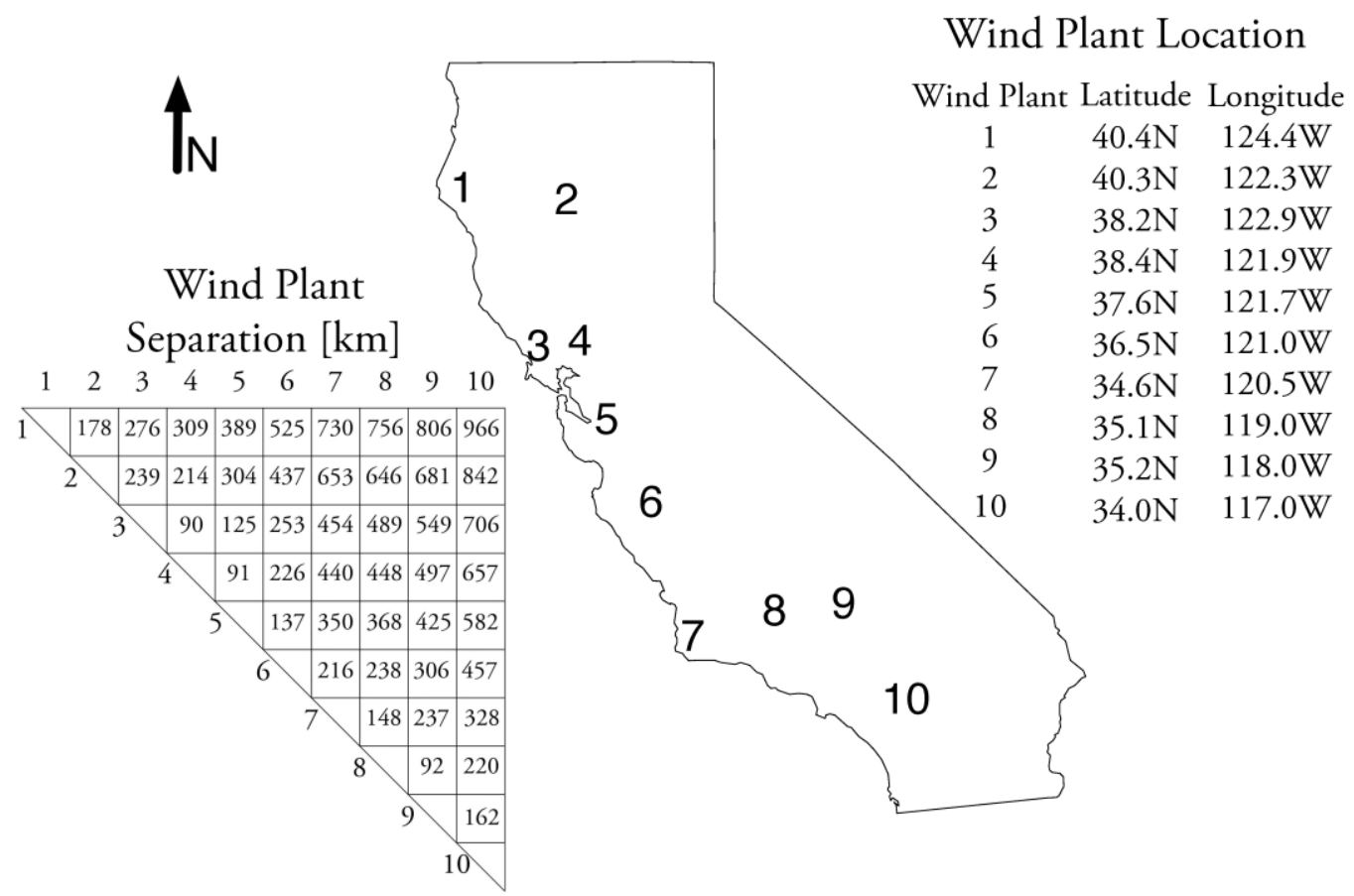

Fig. A.1. Enumeration of the ten CAISO wind sites used to generate all scenarios. Wind turbines (Table A.1) were successively aggregated (Table A.2) from the Wind Toolkit [32] to compose a wind plant for a given scenario (Table 2) and weighted (Table A.2) to achieve a total capacity (Table 2) that was uniformly distributed at each of the ten wind plants.

Table A.1

Wind turbine site identifications [32] located near, and considered as part of, the wind plants (Figure A.1); all wind turbines are located in the California ISO.

\begin{tabular}{|c|c|c|c|c|c|c|c|c|c|c|}
\hline \multirow{2}{*}{$\begin{array}{l}\text { Aggregation } \\
\text { Level }\end{array}$} & \multicolumn{10}{|c|}{ Wind Turbine Site IDs as Located in CAISO } \\
\hline & 1 & 2 & 3 & 4 & 5 & 6 & 7 & 8 & 9 & 10 \\
\hline 1 & 79930 & 82860 & 65251 & 64409 & 56121 & 45512 & 36136 & 34853 & 35705 & 24310 \\
\hline 2 & 76646 & 82631 & 63266 & 63462 & 56122 & 43112 & 35000 & 34674 & 36008 & 24172 \\
\hline 3 & 76057 & 82632 & 66780 & 62267 & 56123 & 47177 & 34829 & 35030 & 35862 & 24173 \\
\hline 4 & 75874 & 82633 & 67290 & 62026 & 56344 & 47043 & 36135 & 34493 & 35704 & 24311 \\
\hline 5 & 75875 & 82167 & 60033 & 62025 & 56124 & 47178 & 35683 & 34852 & 36007 & 24455 \\
\hline 6 & 75876 & 82168 & 59814 & 62027 & 56345 & 47323 & 35843 & 35221 & 36150 & 24042 \\
\hline 7 & 75877 & 82169 & 67025 & 62024 & 56568 & 47044 & 35682 & 35029 & 36006 & 24174 \\
\hline 8 & 75684 & 80391 & 59378 & 62028 & 56346 & 47179 & 34264 & 35220 & 35548 & 24312 \\
\hline 9 & 75685 & 79765 & 59813 & 62023 & 56569 & 47324 & 34999 & 34673 & 35861 & 24586 \\
\hline 10 & 75686 & 79766 & 60259 & 62029 & 56125 & 49148 & 34265 & 34492 & 36149 & 23899 \\
\hline 11 & 75687 & 79767 & 60475 & 61790 & 56570 & 49147 & 34463 & 34851 & 35392 & 24043 \\
\hline
\end{tabular}




\begin{tabular}{|c|c|c|c|c|c|c|c|c|c|c|}
\hline 12 & 75490 & 79594 & 59379 & 61791 & 56347 & 48892 & 34266 & 35219 & 35549 & 24456 \\
\hline 13 & 75491 & 79595 & 69007 & 61789 & 56571 & 49302 & 34464 & 35391 & 36148 & 24175 \\
\hline 14 & 75492 & 79596 & 64045 & 61792 & 56126 & 49301 & 34096 & 35028 & 35703 & 24313 \\
\hline 15 & 73288 & 79395 & 58908 & 62813 & 56803 & 49443 & 34267 & 35390 & 36005 & 23900 \\
\hline 16 & 73289 & 79396 & 72865 & 61788 & 56804 & 48313 & 34828 & 34672 & 35221 & 24044 \\
\hline 17 & 73290 & 79397 & 72864 & 61793 & 56572 & 48432 & 34097 & 34491 & 36147 & 24587 \\
\hline 18 & 73083 & 79394 & 73086 & 61787 & 56348 & 48314 & 32834 & 35389 & 35391 & 24176 \\
\hline 19 & 73084 & 79393 & 58463 & 61794 & 56805 & 48538 & 33203 & 35218 & 36287 & 24457 \\
\hline 20 & 73085 & 79392 & 73085 & 61564 & 56127 & 48433 & 37916 & 34850 & 35860 & 23762 \\
\hline 21 & 72863 & 79201 & 72863 & 61565 & 56573 & 48315 & 37269 & 34297 & 36286 & 23901 \\
\hline 22 & 73086 & 79202 & 73084 & 61563 & 57038 & 48539 & 31323 & 35547 & 36288 & 24314 \\
\hline 23 & 72864 & 79200 & 63267 & 61566 & 56806 & 48434 & 31322 & 35548 & 35547 & 24045 \\
\hline 24 & 72865 & & 73290 & 61562 & 56349 & 48540 & 31321 & 35546 & 36285 & 24177 \\
\hline 25 & 80391 & & 73083 & 61567 & 57039 & & 31320 & 35027 & 35393 & 23763 \\
\hline 26 & & & 61558 & & & & & & 35550 & 23623 \\
\hline 27 & & & 73289 & & & & & & 35702 & 24458 \\
\hline 28 & & & & & & & & & 35222 & \\
\hline
\end{tabular}

1

2

Table A. 2

Successive aggregation of wind turbines 1-to-N, at a specific weighting, to achieve the specified wind plants (Figure A.1) and wind scenarios (Table 2); all wind plants are located in the California ISO.

\begin{tabular}{|c|c|c|c|c|c|c|c|c|c|c|}
\hline \multirow{2}{*}{ Scenario } & \multicolumn{10}{|c|}{ Wind Power Plants as Located in CAISO: Aggregation Level from 1-N@ Weighting } \\
\hline & 1 & 2 & 3 & 4 & 5 & 6 & 7 & 8 & 9 & 10 \\
\hline Base & 3@0.782 & $3 @ 0.782$ & 3@0.782 & $4 @ 0.853$ & $4 @ 0.782$ & $\underline{4 @ 0.782}$ & 3@0.782 & $3 @ 0.782$ & 3@0.782 & $4 @ 0.782$ \\
\hline 1 & $3 @ 0.940$ & $3 @ 0.940$ & $3 @ 0.940$ & $5 @ 0.752$ & $5 @ 0.940$ & $4 @ 0.940$ & $3 @ 0.940$ & 3@0.940 & $3 @ 0.940$ & $4 @ 0.940$ \\
\hline 2 & 500.987 & $\overline{6 @ 0.840}$ & $5 @ 0.987$ & $7 @ 0.859$ & $\overline{7 @ 0.878}$ & $7 @ 0.987$ & $5 @ 0.987$ & $5 @ 0.987$ & $5 @ 0.987$ & $\overline{7 @ 0.840}$ \\
\hline 3 & $8 @ 0.925$ & $\overline{8 @ 0.896}$ & $\overline{8 @ 0.882}$ & $\overline{9 @ 0.910}$ & $\overline{9 @ 0.956}$ & $\overline{9 @ 0.882}$ & $\overline{8 @ 0.882}$ & $\overline{8 @ 0.896}$ & $\overline{8 @ 0.882}$ & $\overline{9 @ 0.925}$ \\
\hline 4 & 11@1.000 & $\underline{10 @ 1.000}$ & $10 @ 0.987$ & $12 @ 0.918$ & $12 @ 0.952$ & $\underline{12 @ 0.963}$ & $\underline{11 @ 1.000}$ & $11 @ 0.987$ & $11 @ 1.000$ & $12 @ 0.963$ \\
\hline 5 & $14 @ 0.989$ & $13 @ 0.951$ & 14@0.933 & $14 @ 0.960$ & $14 @ 0.989$ & $14 @ 0.960$ & $14 @ 0.999$ & $14 @ 0.979$ & $15 @ 0.960$ & 14@0.999 \\
\hline 6 & $17 @ 0.971$ & 15@0.995 & $17 @ 0.948$ & $17 @ 0.955$ & $17 @ 0.963$ & $\overline{17 @ 0.940}$ & $\overline{17 @ 0.971}$ & $17 @ 0.955$ & $18 @ 0.987$ & $\overline{18 @ 0.948}$ \\
\hline 7 & $19 @ 0.952$ & $17 @ 0.973$ & $18 @ 0.987$ & $18 @ 0.995$ & $18 @ 0.945$ & $19 @ 0.980$ & $18 @ 0.952$ & $18 @ 0.995$ & $20 @ 0.980$ & $19 @ 0.995$ \\
\hline 8 & $21 @ 0.952$ & $\overline{19 @ 0.971}$ & $21 @ 0.978$ & $20 @ 0.991$ & $20 @ 0.998$ & $20 @ 0.978$ & $20 @ 0.952$ & $20 @ 0.991$ & $22 @ 0.998$ & $22 @ 0.978$ \\
\hline 9 & $23 @ 0.983$ & $22 @ 0.955$ & $24 @ 0.978$ & $23 @ 0.972$ & $23 @ 0.978$ & $23 @ 0.961$ & $23 @ 0.983$ & $23 @ 0.972$ & $26 @ 0.972$ & $25 @ 0.995$ \\
\hline 10 & $25 @ 0.974$ & $23 @ 0.990$ & $27 @ 0.964$ & $25 @ 0.964$ & $25 @ 0.969$ & $25 @ 0.996$ & $24 @ 0.974$ & $25 @ 0.964$ & $28 @ 0.964$ & $27 @ 0.996$ \\
\hline
\end{tabular}

\section{References}

1. Milligan M, Kirby B. Calculating wind integration costs: Separating wind energy value from integration cost Impacts. Technical report. Golden, CO: NREL; July 2009.

2. Barbose $\mathrm{G}$ et al. Costs and benefits of renewables portfolio standards in the United States. Renew Sustainable Energy Rev, 2015; 52: 523-533.

3. Lantz E, Hand M, Wiser R. The past and future cost of wind energy. Technical report. Golden, CO: NREL; May 2012. http://www.nrel.gov/docs/fy12osti/54526.pdf.

4. Wang Q, Wen FS, Yang A, Huang JS. Cost analysis and pricing policy of wind power in China. J Energy Engin, 2011; 137(3): 138-150.

5. Storck P, Grimit E, Teichgraber H. Determining the value of more accurate wind power forecasting in global electricity markets. 2016 AMS Annual Meeting, New Orleans, LA, 2016.

6. Giebel G. The state of the art in short-term prediction of wind power-A literature overview (2nd ed.). Technical report. Paris, France: ANEMOS.plus/SafeWind projects; 2011.

7. Chen N, Qian Z, Nabney IT, Meng X. Wind power forecasts using Gaussian processes and numerical weather prediction. IEEE Trans Power Syst 2014; 29(2): 656-665.

8. Dowell J, Pinson P. Very-short-term probabilistic wind power forecasts by sparse vector autoregression. IEEE Trans Smart Grid 2016; 7(2): 763-770.

9. Amjadya N, Keyniaa F, Zareipourb H. Short-term wind power forecasting using ridgelet neural network. Electric Power Syst Res 2011; 81: 2099-2107.

10. Pinson P. Wind energy: Forecasting challenges for its operational management. Stat Science 2013; 28(4): 564-585. 
11. Zhao $\mathrm{J}$ et al. An improved multi-step forecasting model based on WRF ensembles and creative fuzzy systems for wind speed. Appl Energy 2016; 162: 808-826.

12. Tascikaraoglu A, Sanandaji BM, Poolla K, Varaiya P. Exploiting sparsity of interconnections in spatio-temporal wind speed forecasting using Wavelet Transform. Appl Energy 2016; 165: 735747.

13. Zhang W, Wu J, Wang JZ, Zhao GW, Shen L. Performance analysis of four modified approaches for wind speed forecasting. Appl Energy 2012; 99: 324-333.

14. Song Z, Jiang Y, Zhang ZJ. Short-term wind speed forecasting with Markov-switching model. Appl Energy 2014; 130: 103-112.

15. Poncela M, Poncela P, Peran JR. Automatic tuning of Kalman filters by maximum likelihood methods for wind energy forecasting. Appl Energy 2013; 108: 349-362.

16. Han L, Romero CF, Yao Z. Wind power forecasting based on principle component phase space reconstruction. Renew Energy 2015; 81: 737-744.

17. Xu Q et al. A short-term wind power forecasting approach with adjustment of numerical weather prediction input by data mining. IEEE Trans Sustain Energy 2015; 6(4): 1,283-1,291.

18. Yao Z, Wang J, Luo X. Probabilistic wind power forecasting based on logarithmic transformation and boundary kernel. Energy Convers Manag 2015; 96: 440-451.

19. Wan C, Xu Z, Pinson P, Dong ZY, Wong KP. Probabilistic forecasting of wind power generation using extreme learning machine. IEEE Trans Power Syst 2014; 29(3): 1,033-1,044.

20. Botterud A, Zhou Z, Wang J et al. Demand dispatch and probabilistic wind power forecasting in unit commitment and economic dispatch: A case study of Illinois. IEEE Trans Sustain Energy 2013; 4(1): 250-261.

21. Gallego-Castillo C, Cuerva-Tejero A, Lopez-Garcia O. A review on the recent history of wind power ramp forecasting. Renew Sustain Energy Rev 2015; 52: 1,148-1,157.

22. Lu S et al. Machine learning based multi-physical-model blending for enhancing renewable energy forecast-Improvement via situation dependent error correction. 2015 European Control Conference (ECC), July 2015.

23. Botterud A, Wang J, Miranda V, Bessa RJ. Wind power forecasting in U.S. electricity markets. The Electricity Journal 2010; 23(3): 71-82.

24. Wang $\mathrm{J}$ et al. Wind power forecasting uncertainty and unit commitment. Appl Energy 2011; 88: 4,014-4,023.

25. Hodge BM, Florita A, Sharp J, Margulis M, Mcreavy D. The value of improved short-term wind power forecasting. Technical report. Golden, CO: NREL; February 2015. Availalbe at: http://ww w.nrel.gov/docs/fy15osti/63175.pdf.

26. Brancucci Martinez-Anido C, Botor B, Florita AR, Draxl C, Lu S, Fhamann HF, Hodge BM. The value of day-ahead solar power forecasting improvement. Solar Energy 2016; 129: 192-203.

27. McGarrigle EV, Leahy PG. Quantifying the value of improved wind energy forecasts in a poolbased electricity market. Renew Energy 2015; 80: 517-524.

28. Wang Q, Brancucci Martinez-Anido C, Wu H, Florita A, Hodge BM. Quantifying the economic and grid reliability impacts of improved wind power forecasting. IEEE Trans Sustain Energy 2016; DOI: 10.1109/TSTE.2016.2560628.

29. CAISO. What the duck curve tells us about managing a green grid, https://www.caiso.com/Docu ments/FlexibleResourcesHelpRenewables_FastFacts.pdf; 2016 [acccessed 02.11.16]

30. MISO. MISO 2014-2015 winter assessment report. Carmel, IN; May 2015. https://www.misoener gy.org/Library/Repository/Report/Seasonal\%20Market\%20Assessments/2015\%20Winter\%20Ass essment\%20Report.pdf.

31. IIT. The IEEE 118-bus 54-unit 24-hour system. motor.ece.iit.edu/data/JEAS_IEEE118.doc.

32. Draxl C, Clifton A, Hodge BM, McCaa J. The Wind Integration National Dataset (WIND) Toolkit. Appl Energy 2015; 151: 355-366.

33. Zhang $\mathbf{J}$ et al. A suite of metrics for assessing the performance of solar power forecasting. Solar Energy 2015; 111: 157-175. 
34. Vaisala Inc. Final report on the creation of the Wind Integration National Dataset (WIND) Toolkit and API. Technical report. Golden, CO: NREL; April 2016.

35. Martínez-Anido CB, Hodge BM, Palchak D. The impact of distributed wind on bulk power syste m operations in ISO-NE. Technical report. Golden, CO: NREL; September 2014. http://www.nrel .gov/docs/fy14osti/62569.pdf.

36. Lew D et al. The western wind and solar integration study phase 2. Technical report. Golden, CO: NREL; September 2013. http://www.nrel.gov/docs/fy13osti/55588.pdf.

37. CAISO. 2014 annual report on market issues \& performance. Folsom, CA; 2014. http://www.cais o.com/Documents/2014AnnualReport_MarketIssues_Performance.pdf.

38. ISO-NE. Sources of electricity used in 2014. Holyoke, MA; 2014. http://www.isone.com/about/what-we-do/key-stats/resource-mix.

39. CAISO. OASIS, http://oasis.caiso.com/mrioasis/logon.do; 2016 [acccessed 02.11.16]

40. WECC. 2024 common case, www.wecc.biz/TransmissionExpansionPlanning/Pages/Datasets.asp $\mathrm{x} ; 2016$ [accessed 02.11.16]

41. Ela E, Milligan M, Kirby B. Operating reserves and variable generation. Technical report. Golden, CO: NREL; 2011.

42. Energy Exemplar. www.energyexemplar.com/; 2016 [acccessed 02.11.16]

43. Wang Q, Zhang G, McCalley JD, Zheng T, Litvinov E. Risk-based locational marginal pricing and congestion management. IEEE Trans Power Syst 2014; 29(5): 2,518-2528.

44. $\mathrm{Gu} \mathrm{Y}$ et al. A novel market simulation methodology on hydro storage. IEEE Trans Smart Grid 2014; 5(2): 1,119-1,128.

45. Wolsey LA, Nemhauser G L. Integer and combinatorial optimization. Wiley; July 8, 1999.

46. Stoll B, Brinkman B, Townsend A, Bloom A. Analysis of modeling assumptions used in production cost models for renewable integration studies. Technical report. Golden, CO: NREL; January 2016. http://www.nrel.gov/docs/fy16osti/65383.pdf.

47. Lund PD, Lindgren J, Mikkola J, Salpakari J. Review of energy system flexibility measures to enable high levels of variable renewable electricity. Renew Sustain Energy Rev 2015; 45: 785807.

48. De Jong $\mathrm{P}$ et al. Integrating large scale wind power into the electricity grid in the Northeast of Brazil. Energy 2016; 100: 401-415.

49. Ulbig A, Andersson G. Analyzing operational flexibility of electric power systems. Electr Power Energy Syst 2015;72:155-64.

50. Denholm P, Hand M. Grid flexibility and storage required to achieve very high penetration of variable renewable electricity. Energy Policy 2011; 39(3): 1,817-1,830.

51. EnerNex. NSP wind integration study. Knoxville, TN; Aug. 2014. https://www.xcelenergy.com/st aticfiles/xe/PDF/Regulatory/16-App-M-NSP-Wind-Integration-Study-January-2015.pdf. 